\title{
Storm induced Semidiurnal Perturbations to Surges on the US Eastern Seaboard
}

Cee Cee X. Feng ${ }^{1 *}$, Maitane Olabarrieta ${ }^{1}$, Arnoldo Valle-Levinson ${ }^{1}$

${ }^{1}$ Civil and Coastal Engineering Department, University of Florida, Gainesville, FL, 32611, USA

*feng@coastal.ufl.edu

\section{ABSTRACT}

Analysis of 19-year-long tidal gauge records along the US East Coast has revealed the appearance of semidiurnal perturbations to storm surges in the South Atlantic Bight. A total of 85 events with semidiurnal surge amplitudes higher than $20 \%$ of the astronomic tidal amplitude and durations longer than two days were identified. These semidiurnal surge events were triggered by the passage of tropical storms and cold fronts. As a consequence of the storm-induced forcing, observed tides were delayed and partially damped with respect to the predictions. Such delay and damping resulted in a semidiurnal signal on the surge. Parallel-to-shore winds in the shelf region between Cape Hatteras and the South Atlantic Bight were highly correlated with the generation of the semidiurnal perturbations. Increased bottom friction combined with Coriolis acceleration, resulting from enhanced wind-driven alongshore currents, are proposed to be the primary factors delaying and attenuating astronomic tides.

Keywords: Storm surge; surge residuals; astronomic tide; semidiurnal surge; tropical storms. 


\section{INTRODUCTION}

The US eastern coast, during the recent decade, has been frequently affected by extreme storm events. Hurricanes Isabel (2003), Katrina (2005), Ike (2008), Irene (2011), and Sandy (2012) all left their names in the US coastal flooding history, which caused severe socioeconomic loss to the coastal communities. Consequently, there is a pressing need to increase understanding and predicting capabilities for storm surges on coastal waters. During extreme storms, water levels can exceed sea defenses and cause flooding (i.e. Jones and Davies, 2007). Storm surges and astronomic tides both contribute to the high water levels during extreme events. For simplicity, many coastal flooding studies consider a linear superposition of astronomic (or predicted) tides and storm surges in the assessment of high water levels. These studies typically disregard the possible nonlinear interactions between astronomic tides and surges, i.e. tide-surge interactions (e.g. the Nivmar system, Fanjul et al. 2001; NOAA system, Glahn et al. 2009). The pioneering studies of Proudman (1955a,b; 1957) indicated that tide-surge interactions can be relevant, especially in shallow waters. Tide-surge interactions can affect the arrival time and the peak value of the water levels, and consequently the flooding threat.

Tide-surge interactions have been analyzed extensively around the world. Most of these studies have focused on the British Coasts (e.g. Proundman, 1957; Prandle \& Wolf, 1978, Horsburgh \& Wilson, 2007; Jones and Davies, 2007). Relevant surge-tide interactions have also been identified in many other coastal regions, including the Orissa coastline in the Bay of Bengal (e.g. Sinha et al. 1996; 2008; Nayak et al. 2012), the Fujian coast in China (Zhang et al. 2010), the Gulf of Suez at the north end of the Red Sea (Rady et al. 1994; 1998), the Gulf of Mexico during Hurricane Rita 2005 (Rego \& 
Li, 2010), and northeast coasts of North America (Bernier and Thompson, 2007). Tidesurge interactions were observed on the US East Seaboard of the South Atlantic Bight during Hurricane Irene 2011 and Sandy 2012 (Valle-Levinson et al. 2013). However, the dynamic factors, regarding meteorological and hydrodynamic conditions, for triggering the semidiurnal surges in the South Atlantic Bight remain unclear, which become the primary goal of the present study.

\section{BACKGROUND}

One of the consequences of tide-surge interactions is the appearance of periodic oscillations (with the same period as the main astronomic tidal component) in the storm surge, often known as 'semidiurnal residuals' or 'semidiurnal surges' (Horsburgh \& Wilson, 2007, Valle-Levinson et al. 2013). Atmospheric pressure and wind stress usually play an important role in tide-surge interactions. Mercer et al. (2002) showed that the atmospheric pressure contributes the most in triggering barotropic waves in the Grand Bank of Canada. Other studies (e.g. Morey et al. 2006; Rego \& Li, 2010) demonstrated the dominant role of wind forcing in promoting periodic oscillations on the storm surges. Nayak et al. (2012) proposed that nonlinear tide-surge interactions depend on the steepness of the continental shelf and the nearshore wave-induced setup. Thus, physical processes responsible for the appearance of a semidiurnal surge under external forcing are site-specific. Most of the studies have deemed nonlinear bottom friction and nonlinear advection terms in momentum balance as the main mechanisms producing these interactions (e.g. Rego and Li, 2010; Zhang et al. 2010, Idier et al. 2012). In the South 
Atlantic Bight, however, Coriolis accelerations linked to along-shelf wind stress were suggested as the main triggers for the semidiurnal surge (Valle-Levinson et al. 2013).

Horsburgh \& Wilson (2007) considered detided water levels (or 'residuals') (denoted as $R$ ) as a combination of the meteorologically induced low-frequency surge $(S)$ and the tide-surge interaction component ( $I$ ). In other words, residuals are given by $R=S+I$. The authors separated the interaction component $I$ that causes the semidiurnal perturbations into two parts: the phase difference between observed and predicted tide, together with attenuation of observed tide due to a local surge modification caused by the tide.

$$
I=R-S=\underbrace{A \cos (\omega t+\phi)-A}_{\text {observed tide - constant surge }} \cos (\underbrace{\omega t)+\beta A \cos }_{\text {predicted tide }}(\underbrace{\omega t+\pi)}_{\text {local surge modification }}
$$

In Eq.(1), $A$ is the tidal amplitude, $\phi$ is the phase difference between the predicted and observed tide $(\phi<0$ means the observed tide is delayed with respect to the predicted tide), $\omega=2 \pi / T$ is the tidal frequency, $T$ is the tidal period $\left(12.42 \mathrm{hr}\right.$ for the $\mathrm{M}_{2}$ harmonic), and $\beta$ is the ratio of the local surge modification to the tidal amplitude. According to Eq.(1), the interaction component $I$ has the same frequency as the fundamental astronomic tidal component $\left(\mathrm{M}_{2}\right.$ in this study), and therefore is referred to as semidiurnal surge. The amplitude of the semidiurnal surge is proportional to the tidal amplitude $A$.

On one hand, according to Pugh (1987), the surge height is inversely proportional to the total water depth. For wind-induced postive surge events, under the same meteorological forcing, the surge height tends to be smaller at high tide. The local surge 
modification is thereby $180^{\circ}$ out of phase with the predicted tide. The total surge height ( $\beta A \cos (\omega t+\pi)+S)$ is then considered as a combination of the periodic variation with respect to tidal levels and a constant surge $S$ (the low-frequency surge independent on tidal levels). By incorporating the local surge modification into the observed tide, the observed tide shows a tidal amplitude reduction (Figure 1.b). On the other hand, in the absence of a local surge modification, when the observed tide is delayed with respect to the predicted tide, the residual peaks occurs during the falling tide (Figure 1.a). The peak develops in the rising tide when the observed tide is ahead of the predicted. Therefore, if tidal phase variations dominate over the local surge modification, the peak semidiurnal surge will be observed at a rising or a falling tide. Conversely, if local surge modification dominates over the phase shift, then the peak of the semidiurnal surge will occur close to the troughs of tide (Figure 1.b). However, Horsburgh \& Wilson (2007) ignored bottom friction induced tidal damping (i.e. Prinsenberg, 1988; Parker, 1991), which would be offset in this study.

The evidence of tide-surge interactions in the South Atlantic Bight can be traced back to decades ago, when Overland and Myers (1976) reported vigorous tide-surge interactions in Cape Fear estuaries during Hurricanes Hazel (1954), Diane (1955), and Helene (1958) via numerical simulations. Valle-Levinson et al. (2013) indicated that the emergence of semidiurnal surges during Sandy and Irene could be related with the quasistanding character of the tides in the apex of the South Atlantic Bight. In this region, the major axes of the tidal ellipses are oriented perpendicular to the coast, and the $\mathrm{M}_{2}$ component is locally amplified because of the partial reflection along the coast (Blanton et al., 2004). 
The rest of the paper is organized as follows. Data sources are presented followed by a description of the analysis techniques implemented. Results provide a statistical analysis on the occurrence of semidiurnal surges and their characteristics in the South Atlantic Bight, and describe the associated atmospheric and oceanic conditions that favor such oscillations. The last two sections present the dynamical implications of the results, through a linkage between semidiurnal surge and atmospheric forcing, and a summary of the main findings.

\section{DATA SOURCES AND ANALYSIS}

Data from a variety of sources were used to study the semidiurnal surges along the US eastern coast and their connection to meteorological conditions. Water levels, atmospheric pressure, and wind velocity measurements were obtained from the NOAA program "Tides and Currents" (tidesandcurrents.noaa.gov), and the NOAA's National Data Buoy Center (ndbc.noaa.gov). A total of 20 tidal gauges, from Virginia Key (FL) to Montauk (NY), were selected to cover most of the US eastern coast (Figure 2). Sea level observations were collected at 6-minute intervals between 1996 and 2014, which is a period when most stations have usable data. Daily weather maps from the National Center for Environmental Prediction were also used to explore weather conditions during selected atmospheric forcing pulses.

An approach based on harmonic analysis, data filtering, and complex demodulation was developed to detect semidiurnal surges. The main steps followed in the approach are illustrated in Figure 3. At each of the tidal gauges considered, the residuals $(R)$ were computed by subtracting the harmonic tidal predictions from the observed water levels. 
The T_Tide Matlab toolbox (Pawlowicz et al., 2002) was used to determine the predicted tides. The low-frequency surges $(S$ ) were extracted from the total water levels by a lowpass filter (Rosenfeld, 1983) with a cut-off period of $13 \mathrm{hr}$. The high-pass observed tides (hereafter called "observed tides") were obtained by subtracting $S$ from the total water levels. The interaction components ( $I$ ) were determined by subtracting $S$ from $R$. The semidiurnal surge amplitudes were obtained by demodulating the $I$ time series at the period of $12.42 \mathrm{hr}$.

Harmonic analysis, Hilbert transform, and continuous wavelet transform techniques were compared to determine the best way to extract semidiurnal surges. While harmonic analysis and wavelet techniques were able to isolate semidiurnal surges, these two methods underestimated the amplitude of the semidiurnal perturbations. The Hilbert transform, on the other hand, overestimated the amplitude of semidiurnal surges as it included all signals of frequencies in addition to the semidiurnal.

Although the data analysis was conducted with annual time series, Figure 3 shows a ten-day sample during the passage of Hurricane Floyd in 1999 to illustrate the main steps followed. I (dashed black line in Figure 3.d) revealed significant semidiurnal oscillations between September $14^{\text {th }}$ and $17^{\text {th }}$. The maximum semidiurnal surge amplitude during this event was $\sim 0.5 \mathrm{~m}$.

It is well known the intensity of tide-surge interactions is proportional to the tidal range $A$ (i.e. Proudman 1955a; Prandle and Wolf, 1978; Horsburgh and Wilson, 2007). The ratio of the semidiurnal surge amplitude to the predicted tidal amplitude is taken as $k$. Events with greatest semidiurnal surges were distinguished with the "peaks over a 
threshold" technique to the time series of $k$. The threshold was defined as $k=0.2(20 \%$ of the predicted tidal amplitude) and a total duration of two days. Once an event exceeding the $k$ threshold was identified, the complete duration was defined as the time span when $k$ exceeded the mean of the total 19-years time series of $k$. This procedure was applied to the 20 tidal gauges along the east coast of US. The time series of semidiurnal surge amplitude at each station were used to construct Hovmöller diagrams to explore the propagation characteristics of the semidiurnal surge along the coast. Figure 4 shows an example of the Hovmöller diagram of the semidiurnal surge amplitude obtained during Hurricane Floyd in 1999.

Atmospheric pressure and wind velocity Hovmöller diagrams were also constructed to investigate the link between atmospheric forcing and the amplitude and duration of semidiurnal surges. Wind and atmospheric pressure data gaps were filled with the Standard Meteorological Data package from the nearby NDBC stations (http://www.ndbc.noaa.gov/). The synoptic history of each Tropical Storm (TS) includes meteorological statistics and trajectories. The Tropical Cyclone Reports (formerly known as Preliminary Reports) from the National Hurricane Center (http://www.nhc.noaa.gov/data/\#tcr), as well as the International Best Track Archive for Climate Stewardship (IBTrACS) Data (Knapp et al., 2010), were used to provide information on tropical storms.

\section{RESULTS}

\subsection{Statistical description of the events}


The annual Hovmöller diagrams of the semidiurnal surge amplitude from 1996 to the end of the 2014 hurricane season were plotted and examined (but not shown here because of the large quantity of the existing pictures). Since the threshold depends on the local tidal amplitude, $k \geq 20 \%$ of the predicted tidal amplitude and a total duration of two days, the events identified at the 20 tidal gauges varied from station to station. In general, for events produced by the tropical storms, the propagation pattern of the semidiurnal surges would go parallel with the trajectory of the tropical cyclones. For example, during the event of Hurricane Sandy in 2012, the semidiurnal oscillation in surges extended along the east coast from the central of Florida to the north of New Jersey, which was along with the path of Sandy. However, for other cases, the semidiurnal surges were sensitive to local weather condition, such as the passage of low-pressure systems or cold fronts, and thereby were site-specific.

Among the 20 tidal gauge stations, the semidiurnal surges were consistently the largest at the Fort Pulaski (GA) station (refer to Figure 4), indicating that tide-surge interactions were the most intense there. The events were particularly concentrated in the year of 1996, 1999, 2005, 2007, 2012 and 2014. Based on the 19-years' tidal record at Fort Pulaski (GA), a total of 85 events were detected.

The 85 events were separated into two groups by whether they appeared in hurricane season or non-hurricane season. The division enables a quick look into the differences between the tropical cyclone induced events versus the winter events (such as cold fronts and nor'easters). According to the National Oceanic and Atmospheric Administrator, Hurricane Division [Retrieved from http://www.aoml.noaa.gov/hrd/tcfaq/G1.html on October 27, 2015], though a traditional North Atlantic Hurricane Season is defined from 
June 1st to November 30th, the specific end date of the hurricane season varies annually. To encompass the most of the tropical activities from 1996 to 2014, while to exclude the influence from winter events that started to emerge in Novembers, the hurricane season was identified from June 1st to October 31 st in this study, with a manual adjustment for an exception of Hurricane Noel in 2007. A total of 41 events was included in the hurricane season.

The amplitude of the most frequent semidiurnal surges was in an range of 0.18 to $0.20 \mathrm{~m}$ (Figure 5a). The probability of larger semidiurnal surges decreased monotonically with amplitude (Figure 5.a). The maximum observed amplitude was $0.45 \mathrm{~m}$ and the top 10 events ( 88 percentile) had amplitudes $>0.35 \mathrm{~m}$. In terms of duration, $40 \%$ of the events lasted no more than 3 days and the probability of longer-lasting events decreased exponentially with the duration period (Figure 5.b). The longest event had a duration of 11 days and the 10 longest events lasted over 5.5 days. The distribution of the maximum semidiurnal surge amplitude made no significant differences between the hurricane and non-hurricane seasons (Figure 5.c). The hurricane seasons encompassed the most persistent event with a period of 11-day and a mean period of 4 days for all the events (Figure 5.c). During the non-hurricane seasons, the mean duration was 3 days and the events rarely exceeded 7 days (Figure 5.d). A weak correlation was found between maximum amplitudes and durations for both hurricane and non-hurricane events.

Out of the 85 events, 79 were characterized by a phase delay of the observed tide relative to the predicted tide. The phase delay ranged from -60 to $70 \mathrm{~min}$ and was most frequent between 30 and 50 min (Figure 6.a). A linear relation was found between phase delay and amplitude of the semidiurnal surge (Figure 6.c). Tidal amplitude reduction was 
observed in 72 of the 85 events. In the other 13 events, the tidal amplitude showed either no change or amplification. These events were categorized in the 'zero' bar of the histogram in Figure 6.b. The tidal amplitude reduction ranged between 0 and $0.3 \mathrm{~m}$, with a near-linear relationship between tidal amplitude reduction and semidiurnal surge peak. However, the large data dispersion cannot be ignored (Figure 6.b).

More than $82.4 \%$ of semidiurnal surge peaks occurred in the falling tide, around $4-5$ hrs after the predicted high tide (Figure 7.a). In the other events, $7 \%$ occurred close to the troughs of the tide $(6 \mathrm{hr}), 6 \%$ appeared at the peaks of the tide (-6 hr), and $4.6 \%$ happened on the rising tide (-4-0 hr in the $x$-axis of Figure 7.a). The peak residual appeared in the falling tide rather than the hight tide when the observed tide was delayed relative to the prediction, and when the phase delay was the dominant factor for generation of the semidiurnal surge (Horsburgh and Wilson, 2007).

In addition, $93 \%$ of the events were associated with positive low-frequency surges ( $S$ of 0.2 to $0.8 \mathrm{~m}$, with a mean of $0.3 \mathrm{~m}$ ) and these were associated with a phase delay in the observed tide. The low-frequency surge (referred to as constant surge) was negative in six events. The six events were also accompanied by an advanced phase of the observed tide, and all of them fell into the pool of an increased tidal amplitude. The associated meteorological conditions are described in Section 4.4. A more detailed comparison between the mechanisms for the positive surge and negative surges are discussed in Section 5.2.

\subsection{Description of the most persistent events}

Daily weather maps from NOAA showed that long-lasting semidiurnal surge events were mostly triggered by tropical cyclones. From all the events with duration $>5.5$ days 
(10 events in total), five were triggered by tropical storms or hurricanes, one was produced by a blizzard ('The Groundhog Day Blizzard, February 2011'), and the others were generated by cold fronts. The maximum amplitude of the semidiurnal surge ranged from 0.18 to $0.45 \mathrm{~m}$ (Table 1). Hurricane Ophelia 2005 produced the most persistent event with amplitudes higher than $0.2 \mathrm{~m}$ for 6.7 days, although the maximum amplitude was not as high as in other cases. The second most persistent event started 3 days before the passage of Hurricane Noel (November 2007). The total duration was 11.6 days and the amplitude exceeded $0.2 \mathrm{~m}$ for 2.5 days. The observed tide was delayed and showed a reduced amplitude with respect to the prediction in all these events (except during the Blizzard). All cases occurred during positive surges. The delay and tidal amplitude reduction ranged from 27 to 75 minutes and 0.1 to $0.2 \mathrm{~m}$, respectively. The Groundhog Day Blizzard was exceptional as it produced a negative surge and an advanced phase of the observed tide with respect to the prediction at Fort Pulaski (Table 1). No tidal amplitude reduction was observed during the Blizzard.

Except for the blizzard event, the rest were initiated by winds affecting the region between Cape Hatteras and North Florida. Winds were persistent for at least 3 days and with a dominant along-shelf component. During the Blizzard in February 2011, crossshore atmospheric pressure pulses of 20 to 40 hpa were accompanied by sudden changes in wind direction (Figure 8).

\subsection{Description of the most intense events}

The most intense events were those with the largest amplitudes in the semidiurnal perturbations. They were triggered by both winter storms and tropical storms. Considering the top 10 events with amplitudes $>0.35 \mathrm{~m}$, half of them were produced by 
the passage of hurricanes (Tammy 2005, Floyd 1999, Sandy 2012, Gabrielle 2001 and Irene 1999). The observed tide was reduced in amplitude (from 0.1 up to $0.3 \mathrm{~m}$ ) and delayed (from 39 to 74 minutes) relative to the prediction and had positive surges (see Table 2). The most extreme event was detected on September $30^{\text {th }} 2005$ (Hurricane Tammy). The second most intense events occurred on February $25^{\text {th }} 2004$ with the passage of a winter storm propagating from the Gulf of Mexico to the Atlantic Ocean. The maximum semidiurnal surge amplitude exceeded $0.45 \mathrm{~m}$ in both cases, although the duration in the second case was shorter ( 4.5 days). Atmospheric pressure and wind vector Hovmöller diagrams indicated that these events were triggered by persistent along-shelf winds blowing equatorward (Figure 9). In general, the strongest along-shelf component of the wind produced the highest amplitude of semidiurnal surges. There were two events (Hurricane Tammy in 2005 and a low-pressure system in March 2001) in which a shift of southward winds to northward at Fort Pulaski produced an increase of the amplitude of the semidiurnal surge.

\subsection{Exceptional cases}

During the above extreme (in duration and amplitude) semidiurnal surge events, the observed tide was delayed and attenuated with respect to the predicted tide (with the exception of the blizzard case). Further investigation proved that this was the norm in most of the 85 events. However, six of the 85 events showed an advance and amplification of the observed tides with respect to the predictions and were associated with negative low-frequency surges. These exceptional cases occurred during the nonhurricane seasons, most of them during winter (Figure 10). According to the National Reflectivity Mosaic Maps derived from the NOAA climate service, these events were 
often associated with the passage of fronts or squall lines across the coastline in the midSouth Atlantic Bight. These fronts or squall lines also brought offshore wind in a scale competitive to the wind intensity of tropical storm status.

\subsection{Correlation with atmospheric forces}

It can be found in the Hovmöller diagrams (Figure 8-10) that, besides few "exceptional cases" with fronts or squall lines, the intensity of semidiurnal surge (blue lines) often aroused with upgraded wind intensity (vector fields) in the southward to southwestward direction, and occasionally accompanied with a drop in the atmospheric pressure (filled contours). Statistical T-tests were conducted to examine the significance of the semidiurnal surge response to different atmospheric factors including atmospheric pressure deficit $\Delta P$, wind stress $\left[\tau_{x}^{w}, \tau_{y}^{w}\right]$, and wind direction. The atmospheric pressure deficit was computed as $\Delta P=P_{a}-P_{0}$, where $P_{a}$ is the sea level atmospheric pressure and $P_{0}$ is the mean sea level atmospheric pressure of $1013.25 \mathrm{hpa}$. The wind stress was computed with the drag coefficient formula proposed by Large et al. (1995):

$$
\begin{aligned}
& 1000 \times c_{d}=0.142+0.0764 \times|U|+\frac{2.7}{|U|+10^{-7}} \\
& \tau_{x}^{w}=\rho_{a} c_{d}|U| u \\
& \tau_{y}^{w}=\rho_{a} c_{d}|U| v
\end{aligned},
$$

Where $c_{d}$ is the nondimensional drag coefficient, $|U|=\sqrt{u^{2}+v^{2}}$ is the wind speed $[\mathrm{m} / \mathrm{s}]$, with $u, v$ as two orthogonal wind components (here in normal-to-shore and parallel-to shore directions respectively) $[\mathrm{m} / \mathrm{s}]$, and $\rho_{a}$ is the air density, $1.22\left[\mathrm{~kg} / \mathrm{m}^{3}\right]$. Wind and sea 
level pressure data were all measured at 41008 NDBC buoy. T-test shows that the correlation between the intensity of semidiurnal surge (represented by mean amplitude during each event) and wind stress $(\mathrm{P}$-value $<0.0001)$ was more significant than that with the atmospheric pressure deficit $(\mathrm{P}-\mathrm{value}=0.408)$. In 59 of 85 events with available wind data, the maximum wind stress exceeded 0.4 pa $(|U| \geq 15 \mathrm{~m} / \mathrm{s})$. Southwestward (including south-southwest and west-southwest) winds were prevalent in more than half of those 59 events. Moreover, during Hurricane Ophelia and Hurricane Tammy, the integrated wind stress $\tau^{w}=\sqrt{\left(\tau_{x}^{w}\right)^{2}+\left(\tau_{y}^{w}\right)^{2}}$ (blue) and the semidiurnal surge amplitude were in phase with each other. The time series of the along-shelf wind component (orange line) and the time series of the semidiurnal surge amplitude 'mirrored' each other (Figure 11.a). The semidiurnal surge was weaker but more persistent during Hurricane Ophelia while during Hurricane Tammy was more intense but shorter. This can be explained by the fact that wind velocity was more persistent, but slightly weaker, during Hurricane Ophelia than during Hurricane Tammy.

The scatterplot matrix (Figure 11.b) reveals correlations between one of the pairs in the following variables: semidiurnal surge amplitude $(\widehat{\boldsymbol{A}})$, integrated wind stress $\left(\tau^{w}\right)$, parallel-to-shore wind stress $\left(\tau_{y}^{w}\right)$, and normal-to-shore wind stress $\left(\tau_{x}^{w}\right)$. The intensity of these parameters was represented by the mean absolute values during each event. The wind stress was found most correlated with the semidiurnal surge. The overall correlation between the semidiurnal surge amplitude and the perpendicular-to-shore wind was small $\left(r^{2}=0.18\right)$, whereas the correlation with the mean parallel-to-shore wind stress was as high as $r^{2}=0.63$. Winds were primarily southwestward in both hurricane (Figure 11.c) and non- 
hurricane seasons (Figure 11.d). During hurricane seasons, parallel-to-shore winds (SW, SSW, WSW) were dominant in more than $54 \%$ of the events while during non-hurricane seasons, the ratio also reached to $50 \%$. Further analysis showed that winds with stress over $0.15 \mathrm{~Pa}$ (speed over $10 \mathrm{~m} / \mathrm{s}$ ) blowing consistently for over $18 \mathrm{hr}$ were needed to create a mean semidiurnal surge event (amplitude $=0.15 \mathrm{~m}$ ), regardless of the wind direction. To produce a semidiurnal surge with mean amplitude over $0.20 \mathrm{~m}$, winds of the same strength are required to blow primarily in the parallel-to-shore direction for at least $47 \mathrm{hr}$.

\section{DISCUSSION}

This section describes the possible physical mechanisms producing the semidiurnal surges in the South Atlantic Bight and outlines the analogies and dissimilarities with previous tide-surge interaction studies.

\subsection{Idealized scenarios for semidiurnal surges in the South Atlantic Bight}

The Regional Ocean Modelling System (ROMS) was used to analyze how wind and tides interact in the South Atlantic Bight. The model is three-dimensional, free surface and terrain-following and solves finite-difference approximations of the ReynoldsAveraged Navier-Stokes equations. It uses the hydrostatic and Boussinesq approximations (Chassignet et al., 2000; Haidvogel et al., 2000) with a split-explicit time stepping algorithm (Shchepetkin and McWilliams, 2005; Haidvogel et al., 2008). In this study, the model was implemented in a depth-integrated mode, disregarding baroclinic flows. The computational grid was composed of $1.5 \mathrm{~km}^{2}$ grid cells and the bathymetry was derived from Etopo2 (2-Minute Gridded Global Relief Data from the National Geophysical Data Center - NOAA). The numerical model was forced with the $\mathrm{M}_{2}$ tidal 
amplitudes and phases given by Topex 7.2 tidal database, with flather boundary condition (Flather, 1976) and quadratic bottom friction coefficient of 0.0025 (non-dimentional). A total of 9 scenarios were simulated by combining tidal propagation with a 1.0 Pa spatially and temporally uniform wind stress $(|U|=18 \mathrm{~m} / \mathrm{s})$ and directions increasing from 0 to 315 degrees. The base simulation did not include the effect of wind. Modeled free surface amplitudes and phases (Figure 12) reflect the quasi-standing character of the $\mathrm{M}_{2}$ constituent as observed by Blanton et al. (2004).

Winds from different directions affected the tidal propagation distinctively (Figure 13). The tide was dampened in most of the scenarios, and its amplitude reduction was most pronounced in the mid-South Atlantic Bight and increased with the intensity of the longshore winds. Tidal amplitude reduction maximized $(\sim 0.15 \mathrm{~m})$ with the winds from NE (45 degrees N) and SW (225 degrees N) and was the least when winds blew perpendicular to the shelf (135 and 315 degrees $\mathrm{N})$. In the offshore wind scenarios (270 degrees $\mathrm{N}$ and 315 degrees $\mathrm{N}$ ), tidal amplitudes even increased along the shore from the apex of the bight to Cape Hatteras in North Carolina.

Phase variations were also noticeable and dependent on the wind direction (Figure 14). The phase delay reached maximum values with winds blowing from the southwest, although winds from the south, north and north-east also caused phase lags. Winds blowing from the south and southwest drove currents in the opposite direction of tidal wave propagation over the shelf and should have enhanced the phase delay. On the other hand, currents associated with winds from the shore were the weakest and produced the least phase delay. Both the amplitude reduction and the phase delay had maxima off the coast in the mid-South Atlantic Bight. 
Momentum analysis indicated that the barotropic pressure gradient and bottom friction were, in general, the terms most affected by the non-linear interaction between tides and wind induced currents and surges. The area where bottom friction increased overlapped with the area where the tidal amplitude reduced most. Coriolis acceleration, especially in the cross-shelf direction, was also modified with different wind conditions. Changes in the amplitude of the advective and mixing terms were in general an order of magnitude smaller than those corresponding to bottom friction and Coriolis accelerations except for a few locations along the coast. There was no direct correlation between the momentum-variation and the tidal phase-shift. For different cases, fundamental mechanisms varied.

\subsection{Differences between "positive surge events" and "negative surge events"}

From the statistical analysis, we have see that the most of the semidiurnal surge events were "positive surge events", whereas there were few excepetional cases that were "negative surge events". During the "positive surge events", the observed tide was often delayed and the tidal amplitude reduced. On the other hand, during the "negative surge events, the observed tide preceded the predicted tide and the tidal amplitude increased. The distinction between the two types can be attributed to a set of factors, including, but not limited to, the local surge modification, the wind-induced currents, and the variation in the momentum terms.

\section{Local Surge Modification:}

According to Pugh (1987), wind-induced sea surface slope ( , m) is inversely proportional to the total water depth $h[\mathrm{~m}],=2 / h$, where is the shelf width $[\mathrm{m}]$, 
is the wind speed $[\mathrm{m} / \mathrm{s}]$, and $\left[\mathrm{s}^{2} / \mathrm{m}\right]$ is a parameter that involves gravity, water density and sea surface drag. Under the same wind and geographic conditions, is smaller when $h$ is larger. Therefore, for "positive surge events" ( $>0)$, the local surge modification is 180 degrees out of phase of the predicted tide (Figure 1.b), and a superimposition of the two produces smaller observed tidal oscillation. For "negative surge events" ( $<0)$, the drop in sea surface level thereby would be greater at low tide than at high tide. The local surge modification would then be in phase with the predicted tide (Figure 15). The superimposition of the two would make the observed tidal amplitude larger than the predicted, as observed in the "Exceptional Cases" described in section 4.4.

\section{Current residuals:}

As diagnosed in the previous chapter, the "positive surge events", were mostly triggered by the along-shelf (NE) wind condition (Figure 8, Figure 9), while the "negative events" were most likely due to the offshore (NW) wind condition (Figure 10). In the homogeneous wind cases, the current residuals (tide+wind - tide-only) induced by the NE wind show a strong longshore-component (current velocity up to $1.0 \mathrm{~m} / \mathrm{s}$ ) on the shelf; whereas the ones induced by the NW wind-induced current field were much smaller (see Figure 13). The NW wind triggered several vortices on the shelf but failed to generate either steady offshore flow or longshore flow in the mid of the South Atlantic Bight.

Momentum balance variation: 
The primary mechanisms triggering semidiurnal surges for the positive surge events were diagnosed as the bottom friction and the Coriolis acceleration. Both terms were mainly modified by the intense alongshore currents. The increase of bottom friction resulted on tidal amplitude reduction and tidal phase delay. To specifically analyze the effect of the Coriolis force, two new numerical experiments were conducted in which the effect of Coriolis was disregarded. The first experiment just considered the tidal propagation. The second experiment accounted for both the tidal propagation and a wind field blowing from the NE. When the Coriolis force was taken into account, tidal damping was augmented (by $5 \mathrm{~cm}$ at Fort Pulaski, GA station), while the tidal phase delay was reduced (by 2 degrees at Fort Pulaski, GA station) at the apex of the South Atlantic Bight (Figure 16). Moreover, the tidal ellipses rotated northwards in the presence of the NE wind (Figure $17 \mathrm{~A}, \mathrm{D}$ ). While, in the absence of the Coriolis acceleration, the tidal ellipses became straight lines, and there is little inclination in the tidal ellipses by the effect of the NE wind. Figure 17 (B, E) shows the differences of the inclination angle (degrees, counter-clockwise from E) of the main tidal propagation direction between tideonly and tide+surge simulations. The positive value manifests a northward inclination of the tidal ellipses as a consequence of the effect of the NE wind and such differences were up to 20 degrees. Also, under the NE wind, the tidal orbital velocities reduced in both major and minor axis. When the Coriolis force was considered, the major-axis reduction of the tidal orbital velocities reached up towards $10 \mathrm{~cm} / \mathrm{s}$ more at the apex of the South Atlantic Bight (Figure $17 \mathrm{C}, \mathrm{F}$ ). Therefore, the increase of Coriolis acceleration in the cross-shelf direction (due to the intense along-shelf currents) modified the tidal propagation in the following way: 1) the main tidal propagation direction (or the direction 
of the major axis of the tidal ellipses) was shifted northwards along the shelf between Cape Hatteras and the apex of the South Atlantic Bight; 2) the tidal amplitude at the apex of the South Atlantic Bight decreased; and 3) phase delay in the observed tide was reduced for the quasi-standing tidal area. The Coriolis force forced the flow shoreward resulting in a positive surge along the coast. Increased water depth would enhance the phase speed of the incident tide, and thereby counteract the bottom friction induced phase delay.

For the "negative surge events", wind-induced currents and therefore the enhancement of the bottom friction were weaker. Compared with NE wind, the NW wind showed smaller tidal amplitude reduction and tidal phase delay at the apex of the South Atlantic Bight (Figure 13, Figure 14). In addition, there is little or no extra Coriolis acceleration, such that the tidal propagation direction was barely changed by the NW winds at the apex of the shelf (Figure $17 \mathrm{H}$ ). The amplitude of tidal orbital velocity even increased, which is most likely due to the local surge modification. The idealized case, however, failed to reproduce a phase advance of observed tide (as identified in the observations), probably because the bottom friction term dominated the physical process in the idealized wind case.

\subsection{Differences with previous tide-surge interaction studies}

In the middle of the South-Atlantic Bight, due to the tide-surge interactions, the observed tide was often patterned with a phase delay and a reduction in the tidal amplitudedelayed and reduced during the "positive surge events", whereas in Horsburgh \& Wilson (2007), the positive surges would leadwere related to a phase advance in the observed tide. Horsburgh \& Wilson (2007) deemed that the positive surge would advance 
the tide by enhancing the phase speed of the tidal wave. While this reason could explain the progressive tidal condition, it may not be suitablee for the quasi-standing tidal behavior in the mid-South Atlantic Bight. Previous studies [e.g. Proudman 1955a, b; 1957] showed that the dynamics dominate of the tide-surge interactions process varied for standing waves and progressive waves. For the quasi-standing tide in this study, the phase speed of the tide was small near the coast, meaning the change in the phase speed by the variation of total water depth would not be the key to the phase shift. It appeared that the influence of local surge modification, as well as the current-induced variation other mechanisms in the momentum balance terms out-weighted the influence of the increase of the total water depth on the tidal propagation.

In Equ.(1), proposed by Horsburgh and Wilson (2007), the tidal amplitude was assumed constant. Whereas, in the reality, tidal amplitude could vary from predictions due to the effect of bottom friction and the effects of the Coriolis force. In this study, a modification was made to Eq. (1), considering a more general form in the observed tide, with both phase shift and tidal amplitude change, as shown in Equ. (3). Because in our analysis it is impossible to separate the local surge modification component from the dynamic-induced tidal amplitude damping in the tidal signal, the change in the tidal amplitude includes both effects. In the following revised form, a more general form of tidal amplitude change was introduced. The generation of overtides (such as $\mathrm{M}_{4}$ ) due to the tidal distortion in shallow water was out of the scope of this study and was then not included in Eq. (3):

$$
I=R-S=\underbrace{B \cos (\omega t+\phi)-A}_{\text {observed tide }} \underbrace{\cos (\omega t)=\hat{A} \cos }_{\text {predicted tide }}(\omega t+\theta)
$$


In Eq. (3), $\boldsymbol{B}$ is the observed tidal amplitude, $\boldsymbol{A}$ the predicted tidal amplitude, $\boldsymbol{\phi}$ is the phase difference between the predicted and observed tide, $\phi<0$ means the observed tide is delayed with respect to the predicted tide, $\widehat{\boldsymbol{A}}$ is the semidiurnal surge amplitude and $\widehat{A}=\sqrt{(A-B \cos \phi)^{2}+(B \sin \phi)^{2}}, \boldsymbol{\theta}$ is the phase shift of semidiurnal surge with respect to the predicted tide, $\theta<0$ means peak of semidiurnal residual happened at the falling tide, $\theta=\arctan \left(\frac{(B \sin \phi}{(B \cos \phi-A}\right)$. If the phase shift is zero, the semidiurnal surge is only caused by a change in tidal amplitude.

Applying Eq. (3) to all events with semidiurnal surges yields a regression coefficient of $r^{2}=0.89$ (Figure 18.a), indicating that the analytical expression captures the main processes that produce the semidiurnal surges. However, Eq. (3) lightly overestimates the maximum amplitudes. The discrepancy perhaps came from the measurement of the tidal phase and amplitude differences, which varied over time. Also, the complex demodulation method itself would smooth the semidiurnal surge signal.

To analyze the sensitivity of the semidiurnal surge amplitude $\widehat{A}$ to tidal amplitude reduction and tidal phase shift. We define $B=(1-\alpha) A$, where $\alpha$ represents the ratio of tidal amplitude reduction to predicted tidal amplitude, since most of the events were associated with tidal damping. Eq.(3) can then be expressed as:

$$
\begin{aligned}
\widehat{A} & =\sqrt{(A-(1-\alpha) A \cos \phi)^{2}+((1-\alpha) A \sin \phi)^{2}} \\
& =A \sqrt{1-2(1-\alpha) \cos \phi+(1-\alpha)^{2}} \\
\theta & =\arctan \left(\frac{(1-\alpha) \sin \phi}{(1-\alpha) \cos \phi-1}\right)
\end{aligned}
$$


If there is no phase difference, the semidiurnal surge amplitude increases linearly with tidal amplitude reduction and Eq.(3) simplifies to $\hat{A}=A(1-\alpha)$. Because $\cos \phi$ is an even function, a phase advance or delay produces the same semidiurnal surge amplitude given a fixed $\alpha$. For a given $\phi, \widehat{A}$ increases with $\alpha$ at small $|\phi|$ (Figure 18.b). As $|\phi|$ increases, the increasing tendency of $\hat{A}$ slows down. For $|\phi|>70 \mathrm{~min}$, the amplitude $\hat{A}$ decreases first and later increases as $\alpha$ increases. For $|\phi|$ at $90 \mathrm{~min}, \hat{A}$ always decreases as $\alpha$ increases.

\section{CONCLUSION}

Tidal gauge records covering most of the US east coast were analyzed from 1996 to 2014 to evaluate the relevance of tide-surge interactions. The analysis was performed by combining different filtering techniques designed to extract the time series of the amplitudes of the semidiurnal surges.

The analysis revealed that semidiurnal surges were evident in the South Atlantic Bight and were most prominent at the apex (Fort Pulaski station in Georgia). Since 1996, 85 events were identified with relative semidiurnal surge amplitudes $\geq 0.2$ (compared to the predicted tidal amplitude) and duration of at least two days. These events were triggered by tropical storms, the passage of cold fronts and nor'easters. The most persistent semidiurnal surges were mainly associated with hurricanes, while the most intense events were associated with hurricane winds (above Category 2) or nor'easters. More than $82 \%$ of semidiurnal surge events were caused by phase delay and attenuation of the observed tide with respect to the prediction. Consequently, the peak of the 
semidiurnal surge occurred in the falling tide. Six exceptional events were also identified in which the observed tide was ahead and amplified with respect to the predictions. These were associated with cold fronts and squalls propagating from land in the direction perpendicular to the coastline.

Regression analysis between atmospheric factors and semidiurnal surges at the South Atlantic Bight apex, revealed that the emergence of the semidiurnal surges was more correlated with wind stress than atmospheric pressure. The semidiurnal surge events primarily occurred with intense longshore winds $(>10 \mathrm{~m} / \mathrm{s})$ in the coastal region of the South Atlantic Bight. However, semidiurnal surges also appeared with winds perpendicular to shore during hurricanes or during the passage of parallel to shore prefrontal squalls. Requirements to produce a semidiurnal surge with mean amplitude over $0.20 \mathrm{~m}$, include winds over $10 \mathrm{~m} / \mathrm{s}$ blowing in the longshore direction for at least $47 \mathrm{hr}$.

Over $50 \%$ of the semidiurnal surges were triggered by along-shore winds, and the observed phase delay and amplitude attenuation could be explained by the increase of bottom friction from an increase in current speed. This hypothesis was further explored with the application of the ROMS numerical model to the South Atlantic Bight. Numerical results showed that the change in tidal amplitude and phase were the greatest at the apex of the South Atlantic Bight. The physics differ for the NE wind induced "positive surge event" and the offshore-wind induced "negative surge event". Although the tidal amplitude reduction and phase delays were modeled adequately, none of the homegeneous wind scenarios were able to reproduce the advanced phase phenomenon as been observed in the six "exceptional cases", which will be a subject of future work. 
Acknowledgments. The authors acknowledge funding from NSF project OCE-1332718. Observed total water levels were obtained from the NOAA program "Tides and Currents" (http://tidesandcurrents.noaa.gov/stations.html?type=Water+LevelsC:IUsers $\backslash$ feng_coastal $\underline{\text { Downloads } \backslash \text { tidesandcurrents.noaa.gov) and atmospheric forcing data are available from }}$ the NDBC buoy stations (http://www.ndbc.noaa.gov/). The Tropical Cyclone Reports (formerly known as Preliminary Reports) are from the National Hurricane Center (http://www.nhc.noaa.gov/data/\#tcr), and the International Best Track Archive for Climate Stewardship (IBTrACS) Data are available from https://www.ncdc.noaa.gov/ibtracs/.

\section{REFERENCES}

Álvarez Fanjul, E., Pérez Gómez, B., \& Rodríguez Sánchez Arévalo, I. (2001). Nivmar: A storm surge forecasting system for Spanish Waters. Scientia Marina, 65(S1), 145-154.

Bernier, N. B., \& Thompson, K. R. (2007). Tide-surge interaction off the east coast of Canada and northeastern United States. Journal of Geophysical Research: Oceans (1978 - 2012), 112(C6).

Chassignet, E.P., H.G. Arango, Dietrich, D., Ezer, T., Ghil, M., Haidvogel, D.B., Ma, C.-C., Mehra, A., Paiva, A.M. \& Sirkes, Z., 2000. DAMEE-NAB: The Base Experiments, Dynamics of Atmospheres and Oceans, 32, 155-183.

Chen, N., Han, G., Yang, J., \& Chen, D. (2014). Hurricane Sandy storm surges observed by HY - 2A satellite altimetry and tide gauges. Journal of Geophysical Research:

Oceans, 119(7), 4542-4548. 
Doodson, A. T. (1956). Tides and storm surges in a long uniform gulf.Proceedings of the Royal Society of London. Series A. Mathematical and Physical Sciences, 237(1210), 325-343.

Emery, W. J. and R. E. Thomson. Data Analysis Methods in Physical Oceanography. Elsevier, 2d ed., 2004. 533-539.

Flather, R. A., 1976: A tidal model of the northwest European continental shelf. "Memoires de la Societe Royale de Sciences de Liege, 6, 141-164.

Glahn B., Taylor A., Kurkowski N, Shaffer W. (2009) The role of the SLOSH model in national weather service storm surge forecasting. Natural Weather Dig, 33(1), 3-14.

Grinsted, A., J. C. Moore, S. Jevrejeva (2004). Application of the cross wavelet transform and wavelet coherence to geophysical time series, Nonlinear Processes in Geophysics, 11, 561566.

Haidvogel, D. B. , Arango, H.G., Budgell, W. P., Cornuelle, B. D., Curchitser, E., Di Lorenzo, E., Fennel, K., Geyer, W. R., Hermann, A. J., Lanerolle, L., Levin, J., McWilliams, J. C., Miller, A. J., Moore, A. M., Powell, T. M., Shchepetkin, A. F., Sherwood, C. R., Signell, R. P., Warner, J. C. \& Wilkin, J., (2008). Regional Ocean Forecasting in Terrainfollowing Coordinates: Model Formulation and Skill Assessment. Journal of Computational Physics, 227(7), 3595-3624.

Haidvogel, D.B., H.G. Arango, K. Hedstrom, A. Beckmann, P. Malanotte-Rizzoli, and A.F. Shchepetkin, (2000). Model Evaluation Experiments in the North Atlantic Basin: Simulations in Nonlinear Terrain-Following. Dynamics of Atmospheres and Oceans, 32, 239-281.

Holland, G. (2008). A revised hurricane pressure-wind model. Monthly Weather Review, 136(9), 3432-3445. 
Holland, G. J. (1980). An analytic model of the wind and pressure profiles in hurricanes. Monthly Weather Review, 108(8), 1212-1218.

Holland, G. J., Belanger, J. I., \& Fritz, A. (2010). A revised model for radial profiles of hurricane winds. Monthly Weather Review, 138(12), 4393-4401.

Horsburgh, K. J., \& Wilson, C. (2007). Tide - surge interaction and its role in the distribution of surge residuals in the North Sea. Journal of Geophysical Research: Oceans (19782012), 112(C8).

Houston, J. R., \& Dean, R. G. (2011). Sea-level acceleration based on US tide gauges and extensions of previous global-gauge analyses. Journal of Coastal Research, 27(3), 409417.

Idier, D., Dumas, F., \& Muller, H. (2012). Tide-surge interaction in the English Channel. Natural Hazards and Earth System Sciences, 12(12), 3709-3718.

Jones, J. E., \& Davies, A. M. (2007). Influence of non-linear effects upon surge elevations along the west coast of Britain. Ocean Dynamics, 57(4-5), 401-416.

Knapp, K. R., Kruk, M. C., Levinson, D. H., Diamond, H. J., \& Neumann, C. J. (2010). The international best track archive for climatestewardship (IBTrACS) unifying tropical cyclone data. Bulletin of the American Meteorological Society, 91(3), 363-376.

Knutson, T. R., McBride, J. L., Chan, J., Emanuel, K., Holland, G., Landsea, C., ... \& Sugi, M. (2010). Tropical cyclones and climate change. Nature Geoscience, 3(3), 157-163.

Large, W. G., \& Crawford, G. B. (1995). Observations and simulations of upper-ocean response to wind events during the ocean storms experiment. Journal of physical oceanography, 25(11), 2831-2852. 
Mercer, D., J. Sheng, R. J. Greatbatch, and J. Bobanović (2002). Barotropic waves generated by storms moving rapidly over shallow water. Journal of Geophysical Research, 107(C10), 3152, doi:10.1029/2001JC001140.

Mooers, C. N. K.,L.M.Bogert, R. L. Smith and J. G. Pattullo (1968). A compilation of observation from moored current meters and thermographs. Data Rep. 20, Dept. Oceanogr., Oregon State University, Corvallis, 91-92.

Morey, S. L., Baig, S., Bourassa, M. A., Dukhovskoy, D. S., \& O'Brien, J. J. (2006). Remote forcing contribution to storm - induced sea level rise during Hurricane Dennis. Geophysical Research Letters, 33(19).

Nayak, S., Bhaskaran, P. K., \& Venkatesan, R. (2012). Near-shore wave induced setup along Kalpakkam coast during an extreme cyclone event in the Bay of Bengal. Ocean Engineering, 55, 52-61.

Overland, J. E., \& Myers, V. A. (1976). Model of hurricane tide in Cape Fear estuary. Journal of the Waterways Harbors and Coastal Engineering Division, 102(4), 407-424.

Parker, B. B. (1991). TIDAL INTERACTIONS (REVIEW). Tidal Hydrodynamics, 237.

Pawlowicz, R., Beardsley, B., \& Lentz, S. (2002). Classical tidal harmonic analysis including error estimates in MATLAB using T_TIDE. Computers \& Geosciences, 28(8), 929-937.

Prandle, D., \& Wolf, J. (1978). The interaction of surge and tide in the North Sea and River Thames. Geophysical Journal International, 55(1), 203-216.

Prinsenberg, S. J. (1988). Damping and phase advance of the tide in western Hudson Bay by the annual ice cover. Journal of physical oceanography, 18(11), 1744-1751.

Proudman, J. (1955a). The propagation of tide and surge in an estuary.Proceedings of the Royal Society of London. Series A. Mathematical and Physical Sciences, 231(1184), 8-24. 
Proudman, J. (1955b). The effect of friction on a progressive wave of tide and surge in an estuary. Proceedings of the Royal Society of London. Series A. Mathematical and Physical Sciences, 233(1194), 407-418.

Proudman, J. (1957). Oscillations of tide and surge in an estuary of finite length. Journal of Fluid Mechanics, 2(4), 371-382.

Rady, M. A., El-Sabh, M. I., Murty, T. S., \& Backhaus, J. O. (1998). Residual circulation in the Gulf of Suez, Egypt. Estuarine, Coastal and Shelf Science, 46(2), 205-220.

Rady, M. A., El - Sabh, M. I., Murty, T. S., \& Backhaus, J. O. (1994). Tide - surge interaction in the Gulf of Suez, Egypt. Marine Geodesy, 17(1), 45-62.

Rego, J. L., \& Li, C. (2010). Nonlinear terms in storm surge predictions: Effect of tide and shelf geometry with case study from Hurricane Rita. Journal of Geophysical Research: Oceans (1978-2012), 115(C6).

Rosenfeld, L.K. (1983). Low-pass filters the time series x using the PL64 filtered described in WHOI technical report, 85-35, 21.

Shchepetkin, A.F., and McWilliams, J.C., 2005. The regional ocean modeling system (ROMS): a split-explicit, free-surface, topography-following-coordinates ocean model. Ocean Modelling 9, 347-404.

Sinha, P. C., Rao, Y. R., Dube, S. K., Rao, A. D., \& Chatterjee, A. K. (1996). Numerical investigation of tide-surge interaction in Hooghly Estuary, India. Marine Geodesy, 19(3), $235-255$.

Sinha, Prakash C., Indu Jain, Neetu Bhardwaj, Ambarukhana D. Rao, and Shishir K. Dube (2008). Numerical modeling of tide-surge interaction along Orissa coast of India. Natural hazards, 45(3), 413-427. 
Talke, S. A., Orton, P., \& Jay, D. A. (2014). Increasing storm tides in New York Harbor, 18442013. Geophysical Research Letters, 41(9), 3149-3155.

Thiebaut, S., \& Vennell, R. (2010). Observation of a fast continental shelf wave generated by a storm impacting Newfoundland using wavelet and cross-wavelet analyses. Journal of Physical Oceanography, 40(2), 417-428.

Thiebaut, S., \& Vennell, R. (2011). Resonance of long waves generated by storms obliquely crossing shelf topography in a rotating ocean. Journal of Fluid Mechanics, 682, 261-288.

Valle-Levinson, A., Olabarrieta, M., \& Valle, A. (2013). Semidiurnal perturbattions to the surge of Hurricane Sandy. Geophysical Research Letters, 40(10), 2211-2217.

Wolf, J. (1978). Interaction of tide and surge in a semi-infinite uniform channel, with application to surge propagation down the east coast of Britain. Applied Mathematical Modelling, 2(4), 245-253.

Wolf, J. (2009). Coastal flooding: impacts of coupled wave-surge-tide models. Natural Hazards, 49(2), 241-260.

Zhang, W. Z., Shi, F., Hong, H. S., Shang, S. P., \& Kirby, J. T. (2010). Tide - surge Interaction Intensified by the Taiwan Strait. Journal of Geophysical Research: Oceans (197822012), 115(C6). 
Tables

2 Table 1. Tidal and surge characteristics associated with top 10 persistent events (Tropical Cyclone induced events are 3 shadowed).

\begin{tabular}{|c|c|c|c|c|c|c|c|c|c|c|}
\hline & Cold Front & Cold Front & H. Floyd & H. Frances & Cold Front & Blizzard & $\begin{array}{l}\text { Mixed } \\
\text { Fronts }\end{array}$ & H. Ophelia & H. Tammy & H. Noel \\
\hline Time(mm/yy) & Oct-11 & Sep-11 & Sep-99 & Sep-04 & Oct-03 & Feb-11 & Sep-07 & Sep-05 & Sep-05 & Oct-07 \\
\hline Maximum amplitude (m) & 0.40 & 0.18 & 0.42 & 0.22 & 0.20 & 0.28 & 0.21 & 0.31 & 0.46 & 0.25 \\
\hline Maximum ratio & 0.4 & 0.2 & 0.5 & 0.3 & 0.2 & 0.3 & 0.3 & 0.3 & 0.4 & 0.3 \\
\hline Duration(day) & 5.4 & 5.5 & 6.1 & 6.5 & 6.9 & 6.9 & 7.4 & 8.4 & 8.7 & 11.7 \\
\hline $\begin{array}{l}\text { Duration exceeding } \\
\text { threshold (day) }\end{array}$ & 2.8 & 0.5 & 2.4 & 1.6 & 0.3 & 0.5 & 3.8 & 6.7 & 1.5 & 2.2 \\
\hline Low-frequency Surge (m) & 0.8 & 0.4 & 0.3 & 0.3 & 0.3 & -0.2 & 0.5 & 0.5 & 0.8 & 0.5 \\
\hline Delay in phase (min) & 51.8 & 29.4 & 74.5 & 46.1 & 27.1 & -20.6 & 42.2 & 45.0 & 62.5 & 38.2 \\
\hline $\begin{array}{l}\text { Reduction in tidal } \\
\text { amplitude (m) }\end{array}$ & 0.2 & 0.1 & 0.1 & 0.1 & 0.0 & 0.0 & 0.1 & 0.2 & 0.2 & 0.1 \\
\hline $\begin{array}{l}\text { Min astronomic tidal } \\
\text { amplitude }(\mathrm{m})\end{array}$ & 0.9 & 0.8 & 0.7 & 0.7 & 0.9 & 0.8 & 0.6 & 0.9 & 0.9 & 0.9 \\
\hline $\begin{array}{l}\text { Max astronomic tidal } \\
\text { amplitude }(\mathrm{m})\end{array}$ & 1.0 & 1.0 & 1.2 & 1.1 & 1.3 & 1.0 & 1.0 & 1.0 & 1.1 & 1.3 \\
\hline Residual peak (m) & 1.2 & 0.6 & 1.0 & 0.6 & 0.5 & 0.2 & 0.7 & 0.9 & 1.4 & 0.7 \\
\hline
\end{tabular}


6 Table 2. Tide and surge characteristics associated with the top 10 intense events (Tropical Cyclone induced events are 7 shadowed).

\begin{tabular}{|c|c|c|c|c|c|c|c|c|c|c|}
\hline & $\begin{array}{c}\text { H. } \\
\text { Sandy }\end{array}$ & $\begin{array}{l}\text { Low } \\
\text { Pres. } \\
\text { Sys. }\end{array}$ & $\begin{array}{l}\text { Low } \\
\text { Pres. } \\
\text { Sys. }\end{array}$ & $\begin{array}{l}\mathrm{H} . \\
\text { Irene }\end{array}$ & $\begin{array}{c}\mathrm{H} . \\
\text { Gabrielle }\end{array}$ & $\begin{array}{l}\text { Low } \\
\text { Pres. } \\
\text { Sys. \& } \\
\text { Precip. }\end{array}$ & $\begin{array}{l}\text { Cold } \\
\text { Front }\end{array}$ & $\begin{array}{l}\text { H. } \\
\text { Floyd }\end{array}$ & Blizzard & $\begin{array}{l}\text { H. } \\
\text { Tammy }\end{array}$ \\
\hline Time $(\mathrm{mm} / \mathrm{yy})$ & Oct-12 & Mar-96 & Mar-01 & Oct-99 & Sep-01 & Dec-97 & $\begin{array}{l}\text { Oct- } \\
11\end{array}$ & Sep-99 & Feb-04 & Sep-05 \\
\hline $\begin{array}{l}\text { Maximum amplitude } \\
\text { (m) }\end{array}$ & 0.35 & 0.35 & 0.36 & 0.37 & 0.39 & 0.40 & 0.40 & 0.42 & 0.45 & 0.46 \\
\hline Maximum ratio & 0.3 & 0.3 & 0.4 & 0.5 & 0.3 & 0.3 & 0.4 & 0.5 & 0.5 & 0.4 \\
\hline Duration(day) & 3.2 & 3.1 & 4.0 & 2.9 & 2.7 & 2.6 & 5.4 & 6.1 & 4.5 & 8.7 \\
\hline $\begin{array}{l}\text { Duration exceeding } \\
\text { threshold (day) }\end{array}$ & 1.9 & 1.7 & 1.6 & 2.2 & 1.0 & 1.4 & 2.8 & 2.4 & 1.3 & 1.5 \\
\hline $\begin{array}{l}\text { Low-frequency Surge } \\
(\mathrm{m})\end{array}$ & 0.4 & 0.3 & 0.6 & 0.5 & 0.5 & 0.2 & 0.8 & 0.3 & 0.6 & 0.8 \\
\hline Delay in phase (min) & 40.6 & 48.2 & 69.0 & 73.0 & 38.7 & 41.7 & 51.8 & 74.5 & 65.2 & 62.5 \\
\hline $\begin{array}{l}\text { Reduction in tidal } \\
\text { amplitude }(\mathrm{m})\end{array}$ & 0.2 & 0.2 & 0.1 & 0.3 & 0.2 & 0.2 & 0.2 & 0.1 & 0.1 & 0.2 \\
\hline $\begin{array}{l}\text { Min Astronomic Tidal } \\
\text { Amplitude }(\mathrm{m})\end{array}$ & 1.1 & 1.0 & 0.8 & 0.7 & 1.0 & 1.1 & 0.9 & 0.7 & 0.7 & 0.9 \\
\hline $\begin{array}{l}\text { Max Astronomic Tidal } \\
\text { Amplitude (m) }\end{array}$ & 1.1 & 1.1 & 1.0 & 0.8 & 1.3 & 1.3 & 1.0 & 1.2 & 1.0 & 1.1 \\
\hline Residual Peak (m) & 0.7 & 0.6 & 1.1 & 1.1 & 0.9 & 0.7 & 1.2 & 1.0 & 1.1 & 1.4 \\
\hline
\end{tabular}

8 
Figures
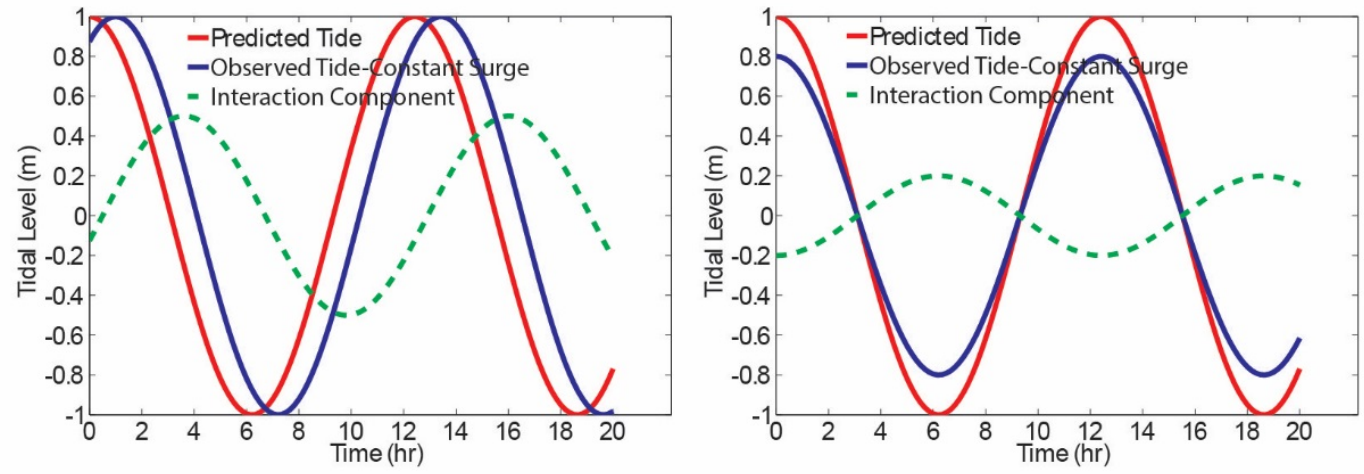

12 Figure 1. Schematic diagram of the generation of semidiurnal surges during positive

13 surge events: a) due to a phase delay of the observed tide; b) due to the effect of the local

14 surge modification. The red line represents the predicted tide, the blue line represents the

15 observed tide with adjustment to the mean sea level, and the dashed green line represents

16 the interaction component $(I)$. 


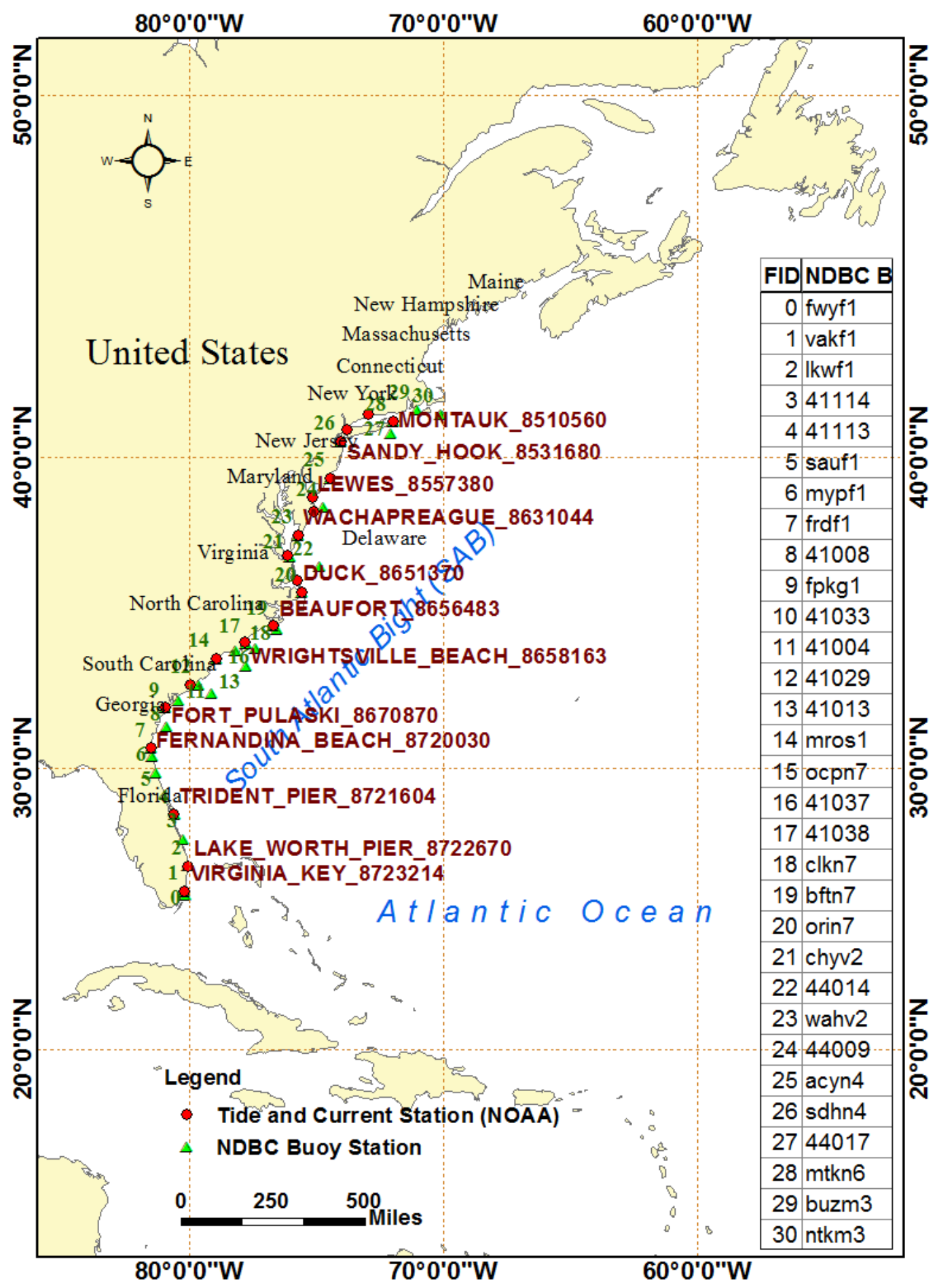

18 Figure 2. Location of tidal gauges (red dots) and buoy stations (green triangles) used for

19 data collection and analysis. 


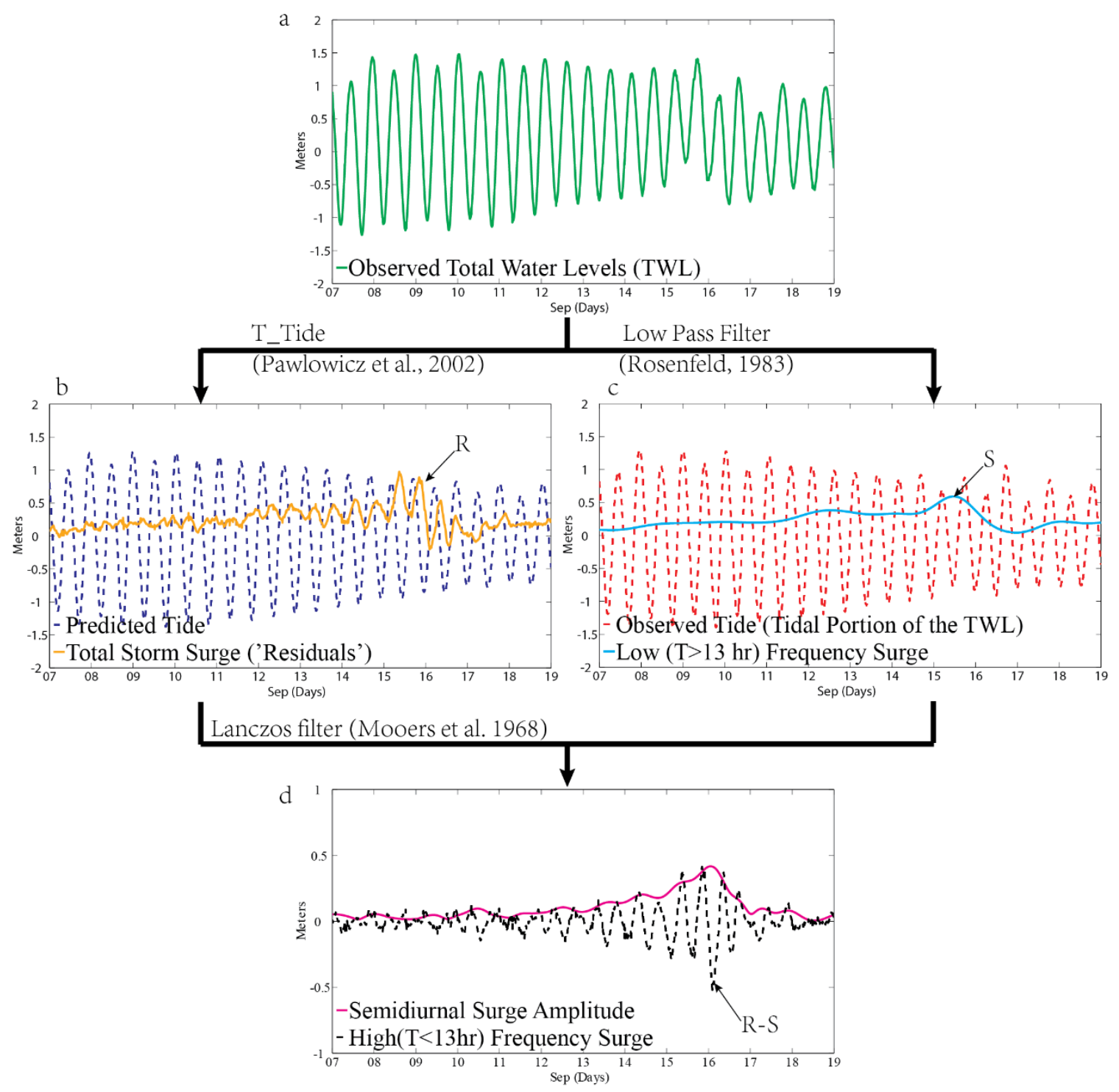

21 Figure 3. Steps followed to extract the surge signal (solid orange in b), the low-frequency

22 surge (solid cyan in c) and the semidiurnal surge amplitude (solid magenta in d). The

23 high-frequency oscillations of the surge signal (dashed black in d) were obtained by

24 subtracting the low-frequency surge $(S)$ from the residuals $(R)$. The specific time series

25 shown in the figure corresponds to data at Fort Pulaski (GA) during the passage of

26 Hurricane Floyd in 1999. 


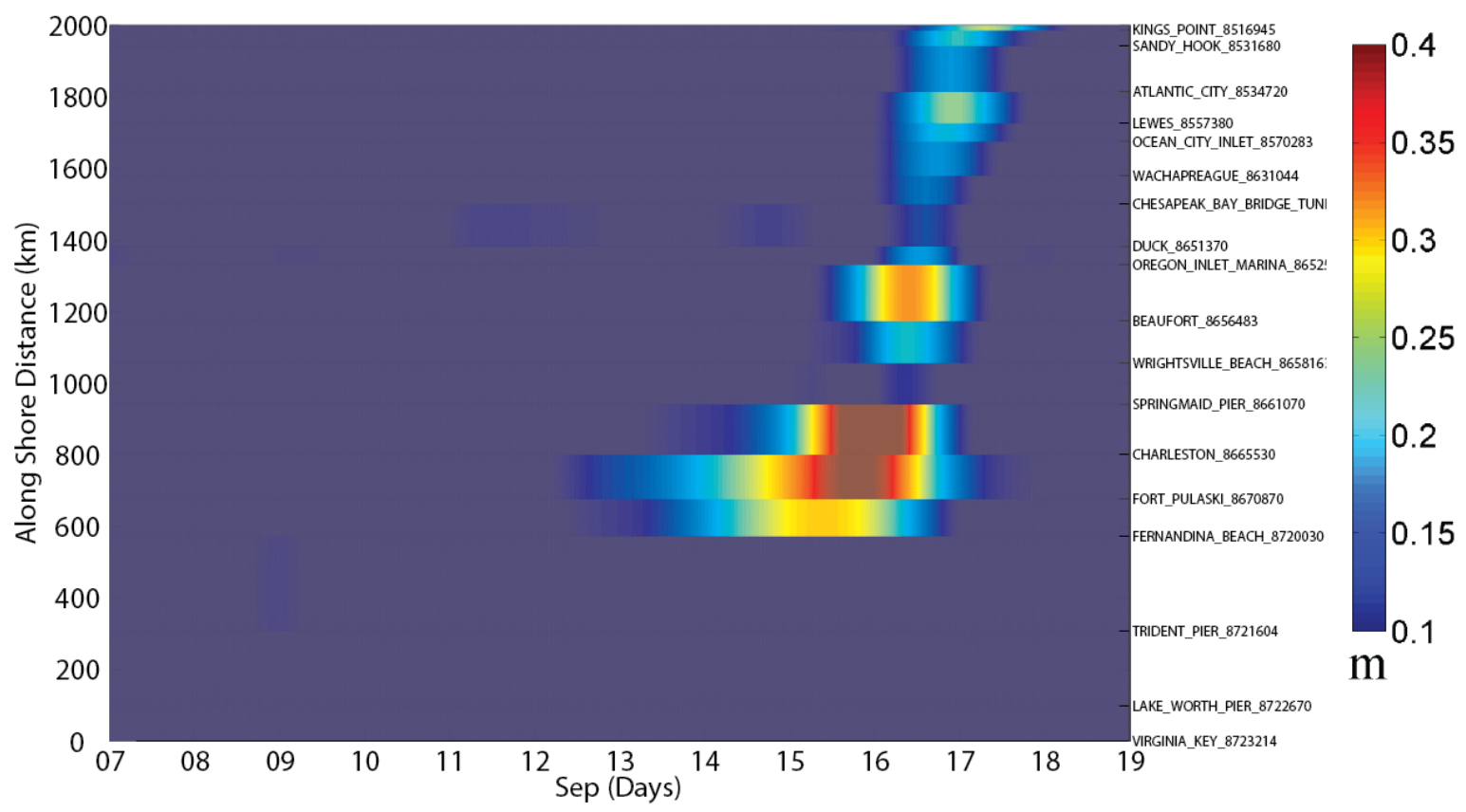

29 Figure 4. Hovmöller diagram of semidiurnal surge amplitude during the passage of

30 Hurricane Floyd in 1999. The distance (in kilometers), indicated by the left y-axis,

31 represents the map distance from a location to the y-axis origin; the origin of the left $y$ -

32 axis in this case is at Virginia Key (FL), on the southern coast of Florida. Labels in the

33 right y-axis correspond to the NOAA's tidal gauge station IDs in Figure 1. Daily weather

34 maps from NOAA were used to determine the meteorological conditions associated with

35 each semidiurnal surge event. 

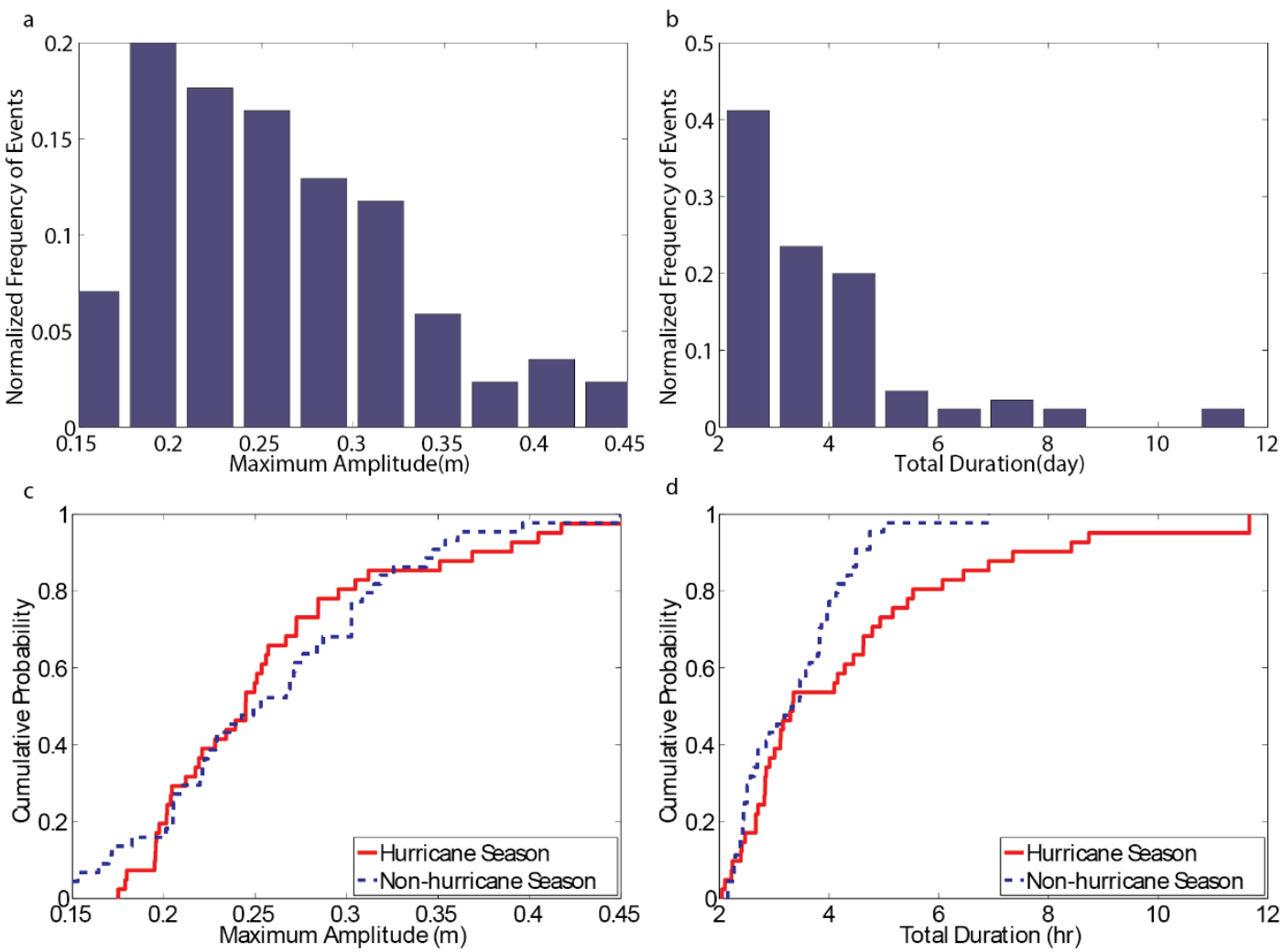

38 Figure 5. a) Histogram of the maximum semidiurnal surge amplitude, b) Histogram of the

39 event duration, c) Empirical cumulative density functions of the maximum amplitude of

40 semidiurnal surge during Hurricane season (solid red) and non-Hurricane season (dashed

41 blue); d) Empirical cumulative density functions of the event duration during Hurricane

42 season (solid red) and non-Hurricane season (dashed blue). 

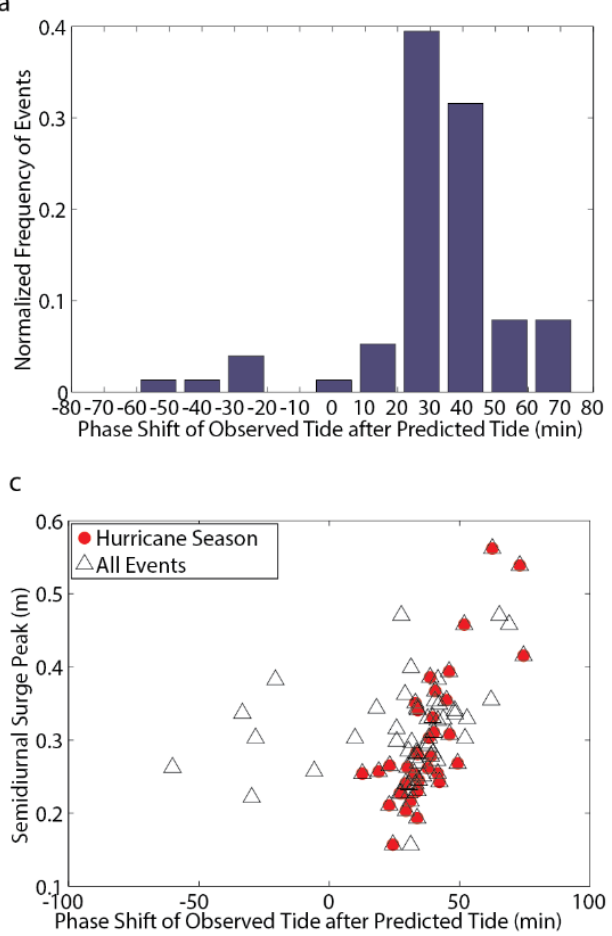

b

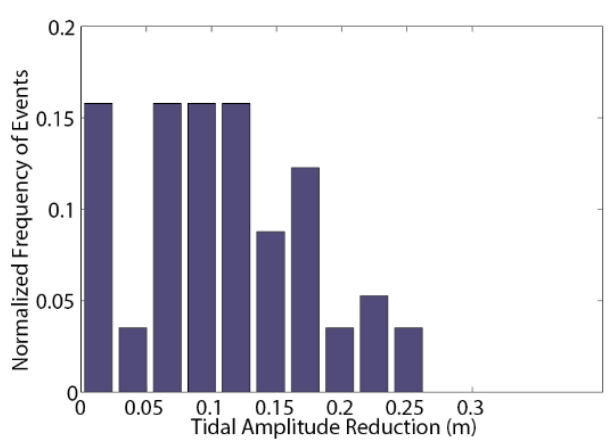

d

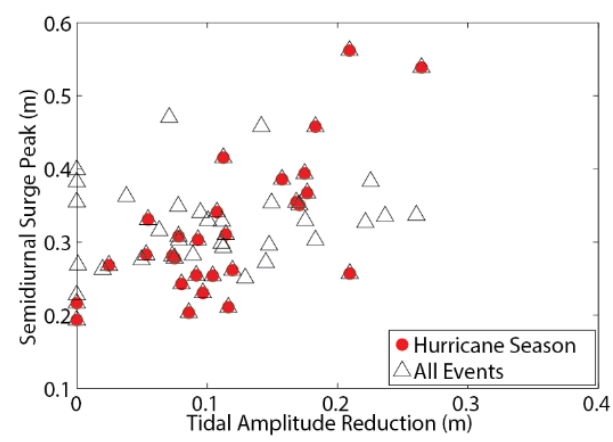

45 Figure 6. a) Histogram of phase shift of the observed tide after high tide, b) Histogram of

46 the tidal amplitude reduction; c) Scatter plot of phase shift versus semidiurnal surge peak

47 and d) Scatter plot of tidal amplitude reduction versus semidiurnal surge peak, for the

48 hurricane season (red circles) and all 85 semidiurnal surge events (triangles). 
a

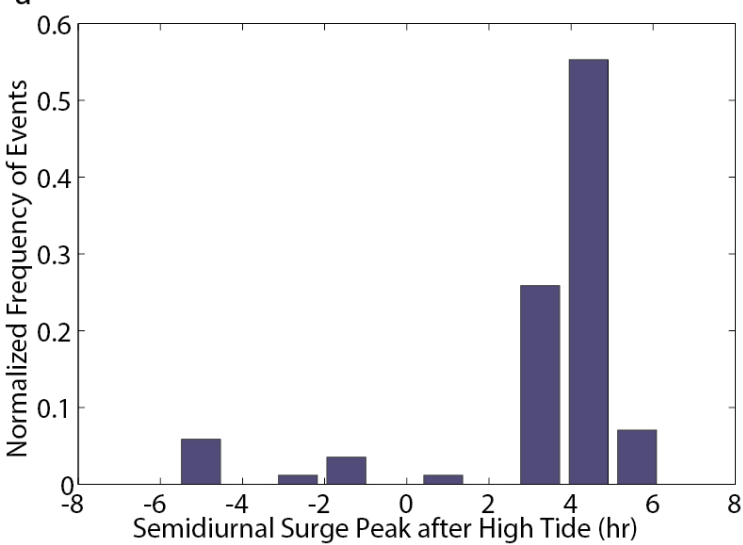

b

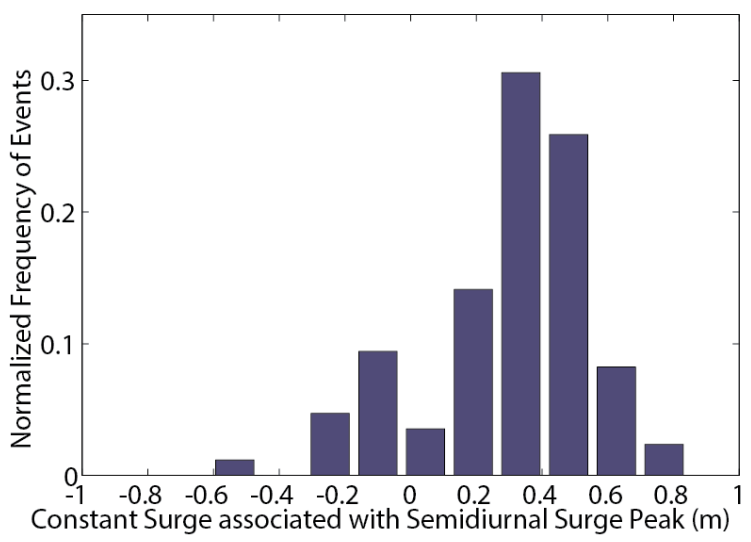

53 Figure 7. a) Histogram of semidiurnal surge peak after high tide, b) Histogram of the

54 meteorologically forced constant surge at the time of semidiurnal surge peak. 

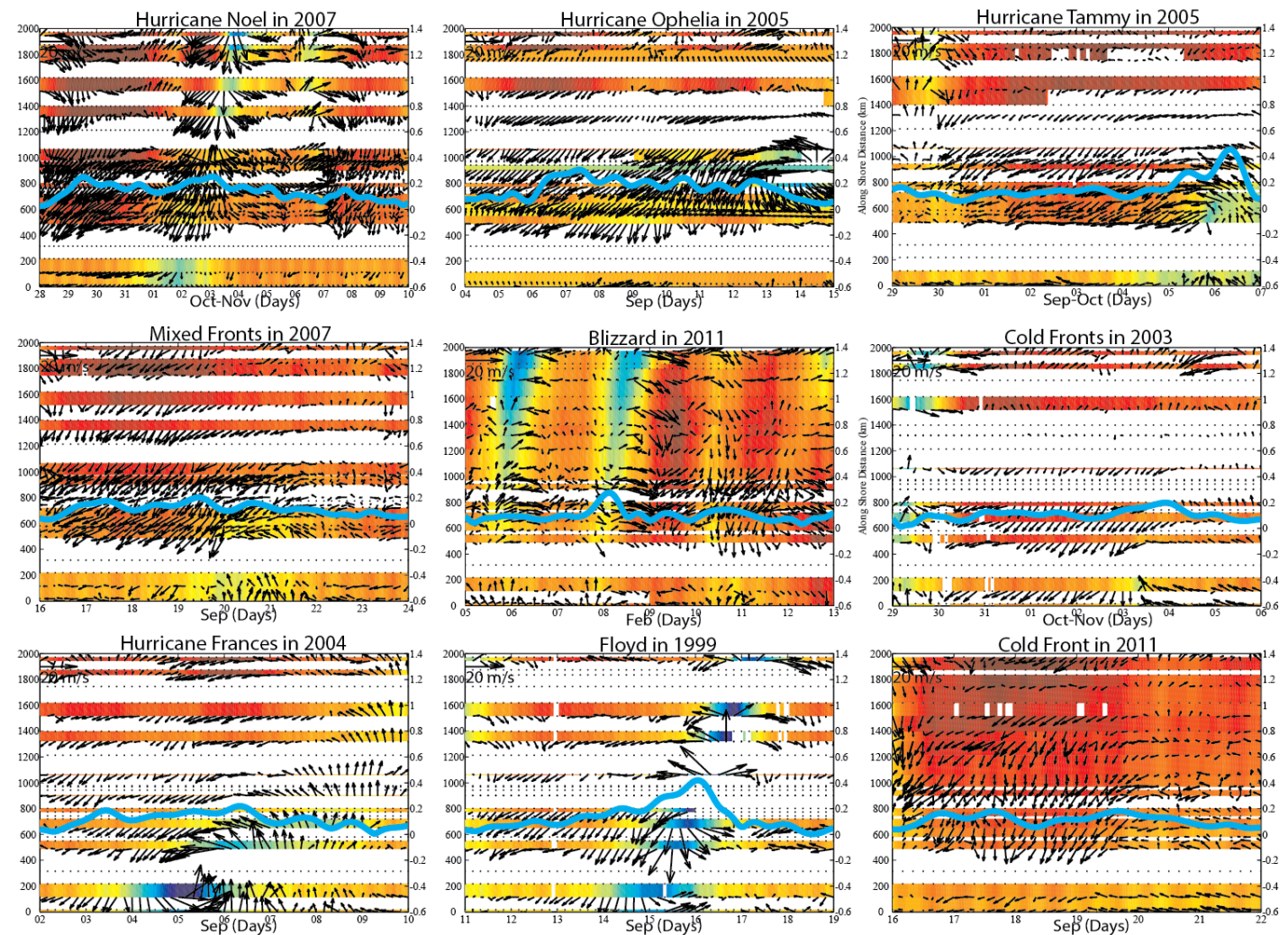

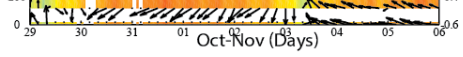
Cold Front in 20
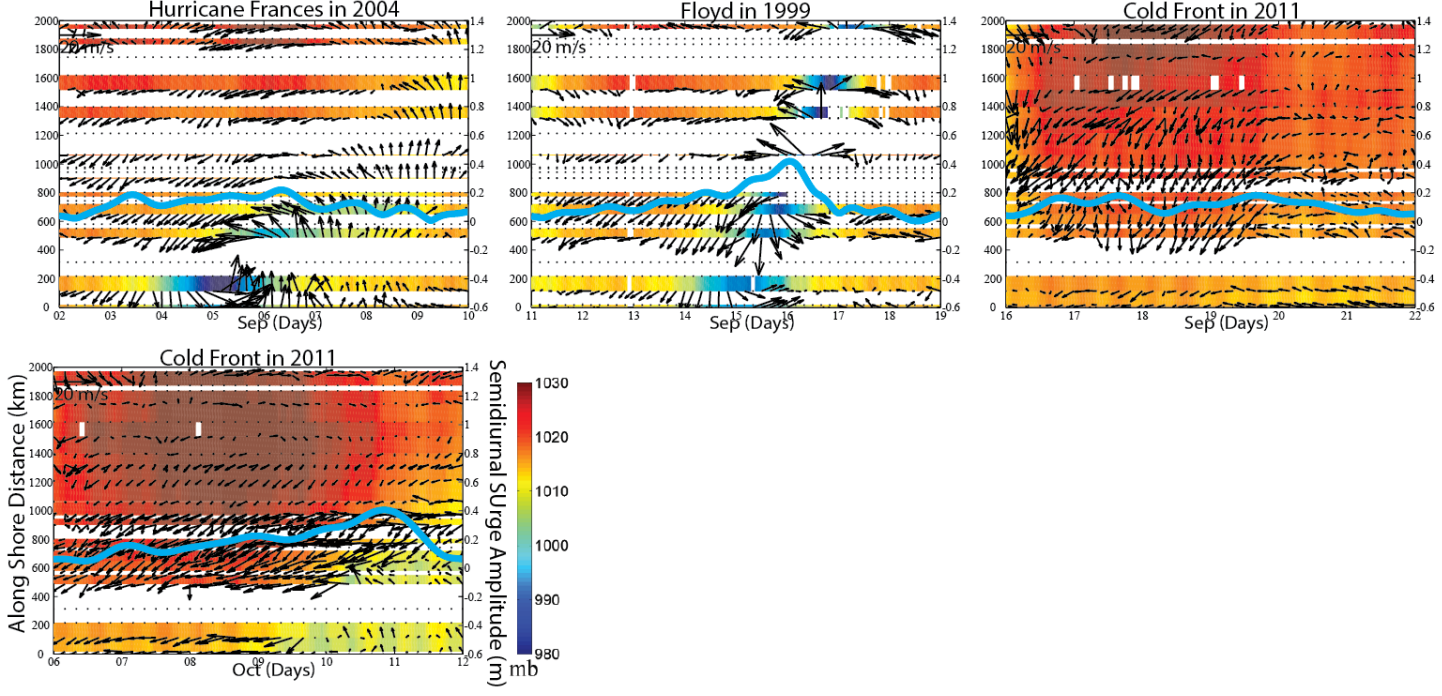
57 Figure 8. Atmospheric pressure and wind vector Hovmöller diagrams of the most persistent semidiurnal surge events. The

58 blue line in the Hovmöller diagrams represents the time series of the amplitude of the semidiurnal surge at Fort Pulaski,

59 Georgia. 

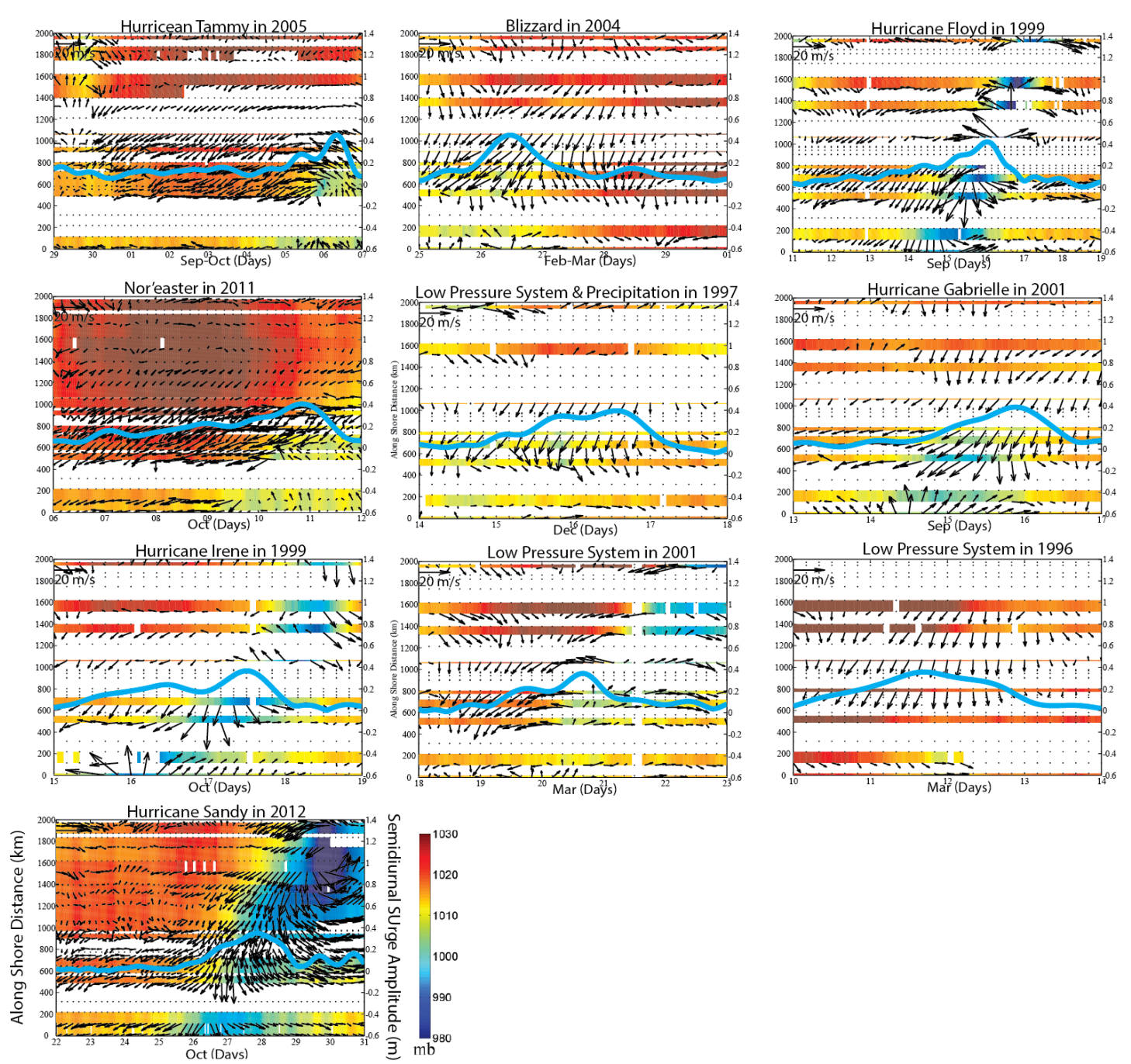

61 Figure 9. Atmospheric pressure and wind vector Hovmöller diagrams of the most intense events. The blue line in the

62 Hovmöller diagrams represents the time series of the amplitude of the semidiurnal surge at Fort Pulaski, Georgia. 

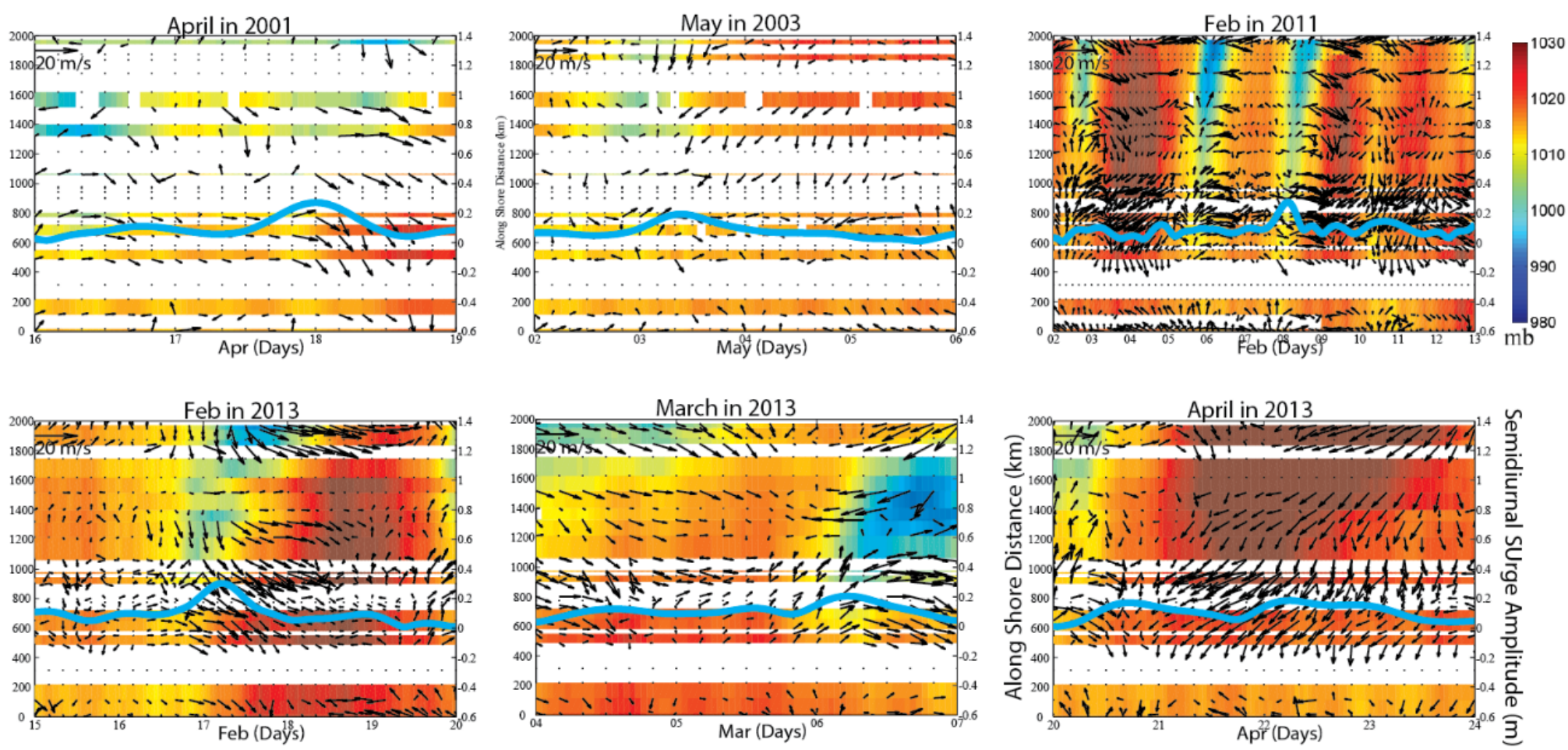

64 Figure 10. Atmospheric pressure and wind vector Hovmöller diagrams of the cases showing phase advances; in the last event

65 (April in 2013), there were two semidiurnal surge amplitude peaks, the earlier one was associated with a phase advance and 
67 Figure 11. a) Time series of semidiurnal surge amplitude (black line) with over threshold

68 event emphasized in thick dashed magenta line, wind stress (blue star line), parallel-to-

69 shore wind stress (orange, negative toward southwestward) and perpendicular-to-shore

70 wind stress (green, negative toward the inland); b) Scatterplot matrix between pairs of the

71 variables with mean absolute values: semidiurnal surge amplitude $(\overline{\bar{A}})$, wind stress $\left(\overline{\tau^{w}}\right)$,

72 parallel-to-shore wind stress $\left(\overline{\tau_{y}^{w}}\right)$ and mean perpendicular-to-shore wind stress $\left.\left(\overline{\tau_{x}^{w}}\right) ; \mathrm{c}\right)$

73 rose wind depicting the wind direction distribution during the semidiurnal surge events of

74 hurricane seasons; d) rose wind illustrating the wind direction distribution during the

75 semidiurnal surge events of non-hurricane seasons. In b), the variables are written in a

76 diagonal line from the top left to bottom right and each square shows the regression

77 between a pair of two. The scatterplot matrix is derived considering the 59 out of 85

78 semidiurnal surge events with available meteorological data. It is automatically ordered

79 and colored by the correlation coefficients with red depicting the highest correlation, and

80 yellow representing the lowest. 


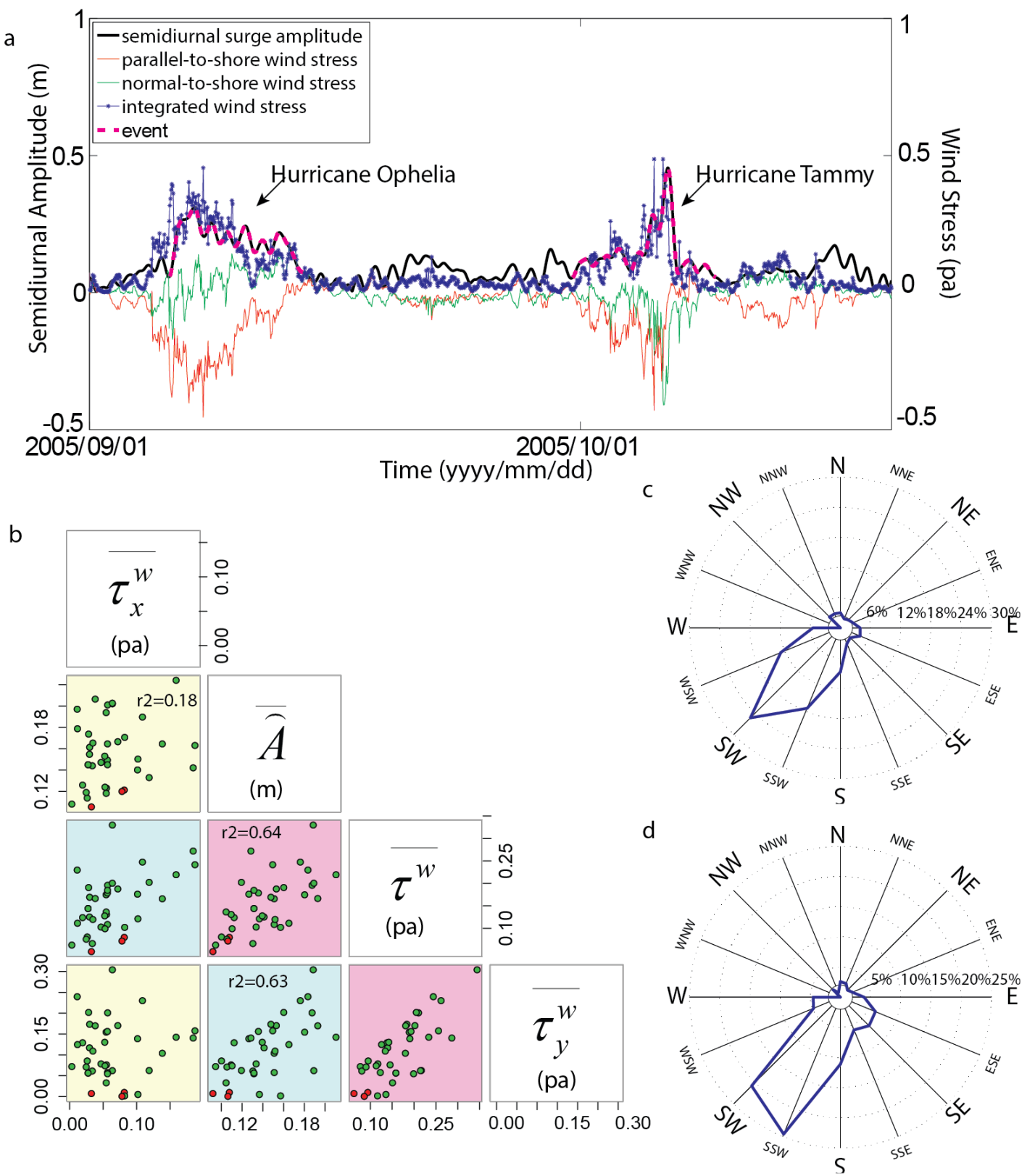




\section{a) Amplitude}

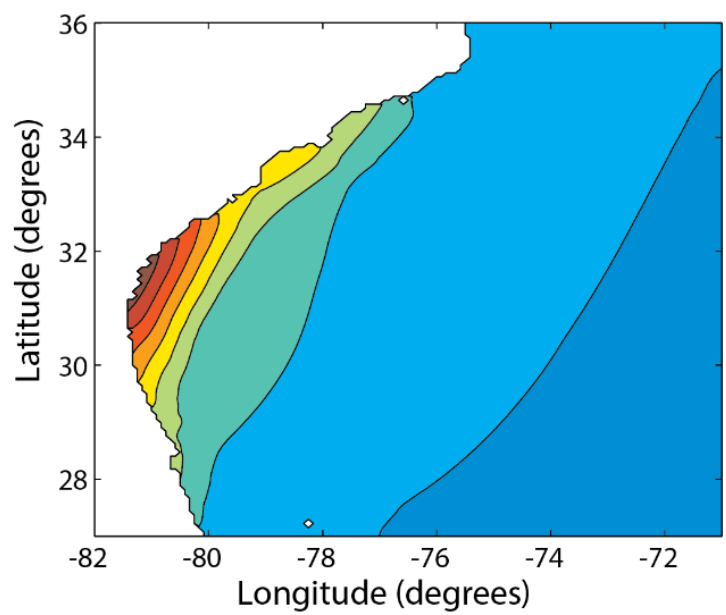

(m)

\section{b) Phase}

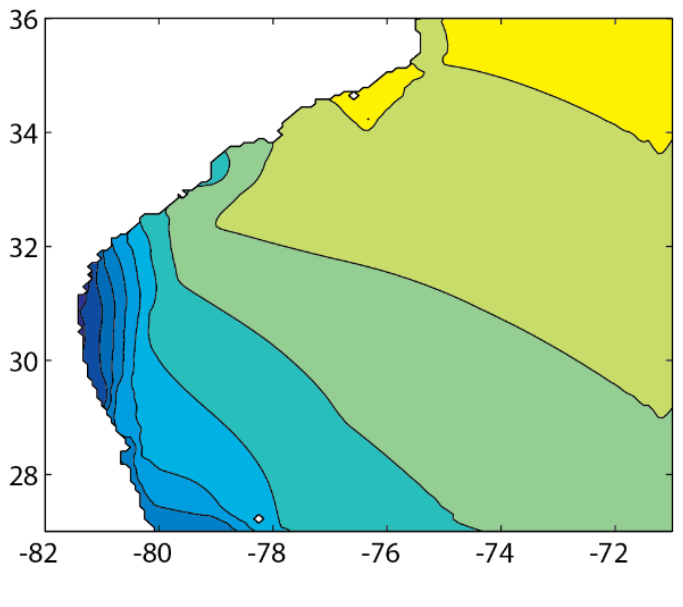

(degrees)
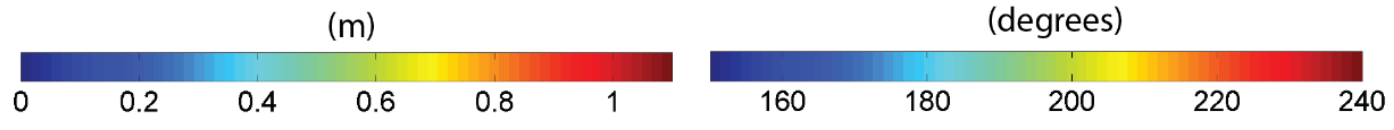

85 Figure 12. Modeled $\mathrm{M}_{2}$ free surface a) amplitude (m) and b) phase (degrees). Results

86 reflect the quasi-standing character of the $\mathrm{M}_{2}$ harmonic as observed by Blanton et al.

87 (2004). 

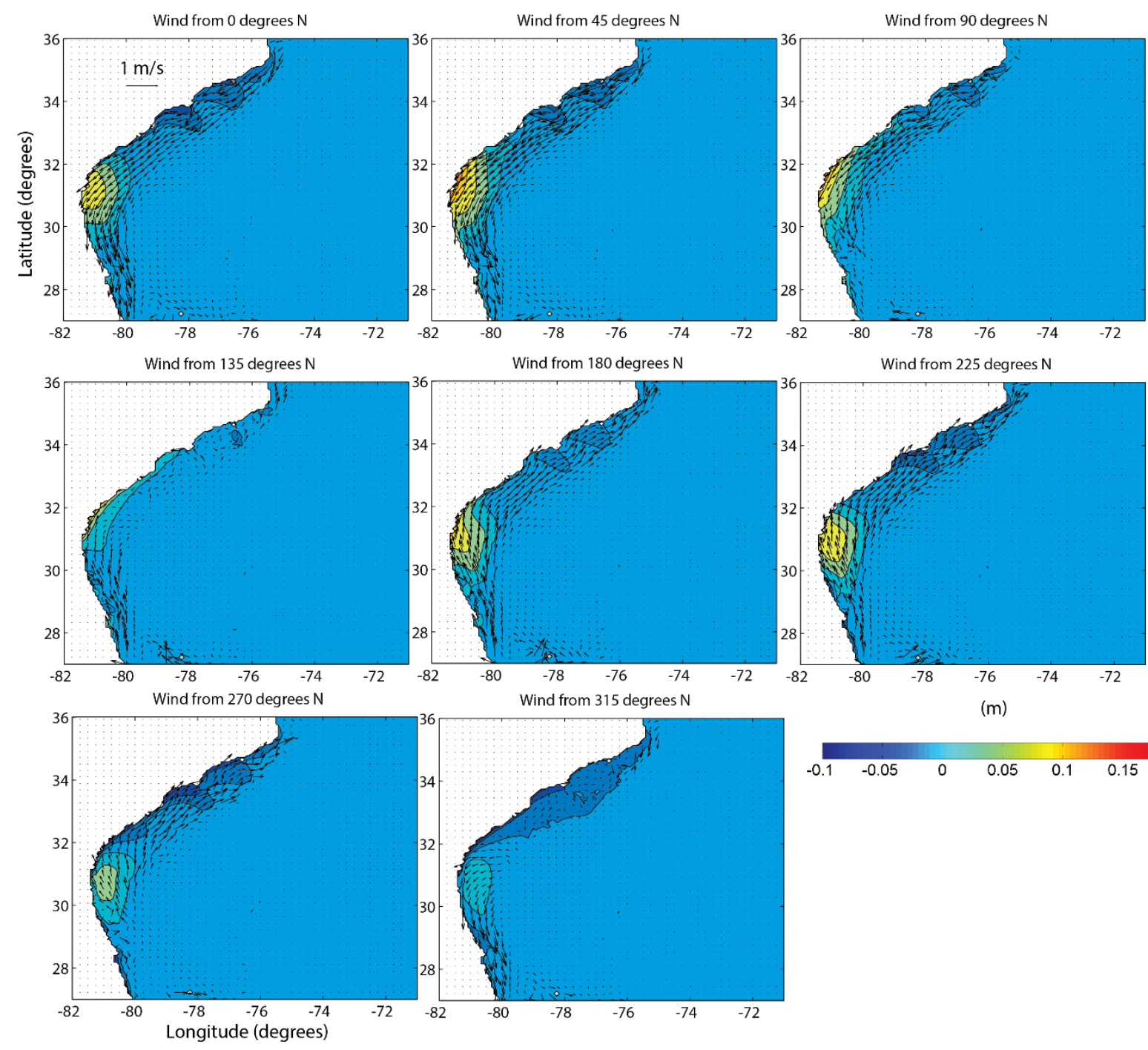

(m)

89 Figure 13. Modeled $\mathrm{M}_{2}$ free surface amplitude reduction (m) and wind-induced depth-

90 averaged current vectors as a function of the wind direction. 

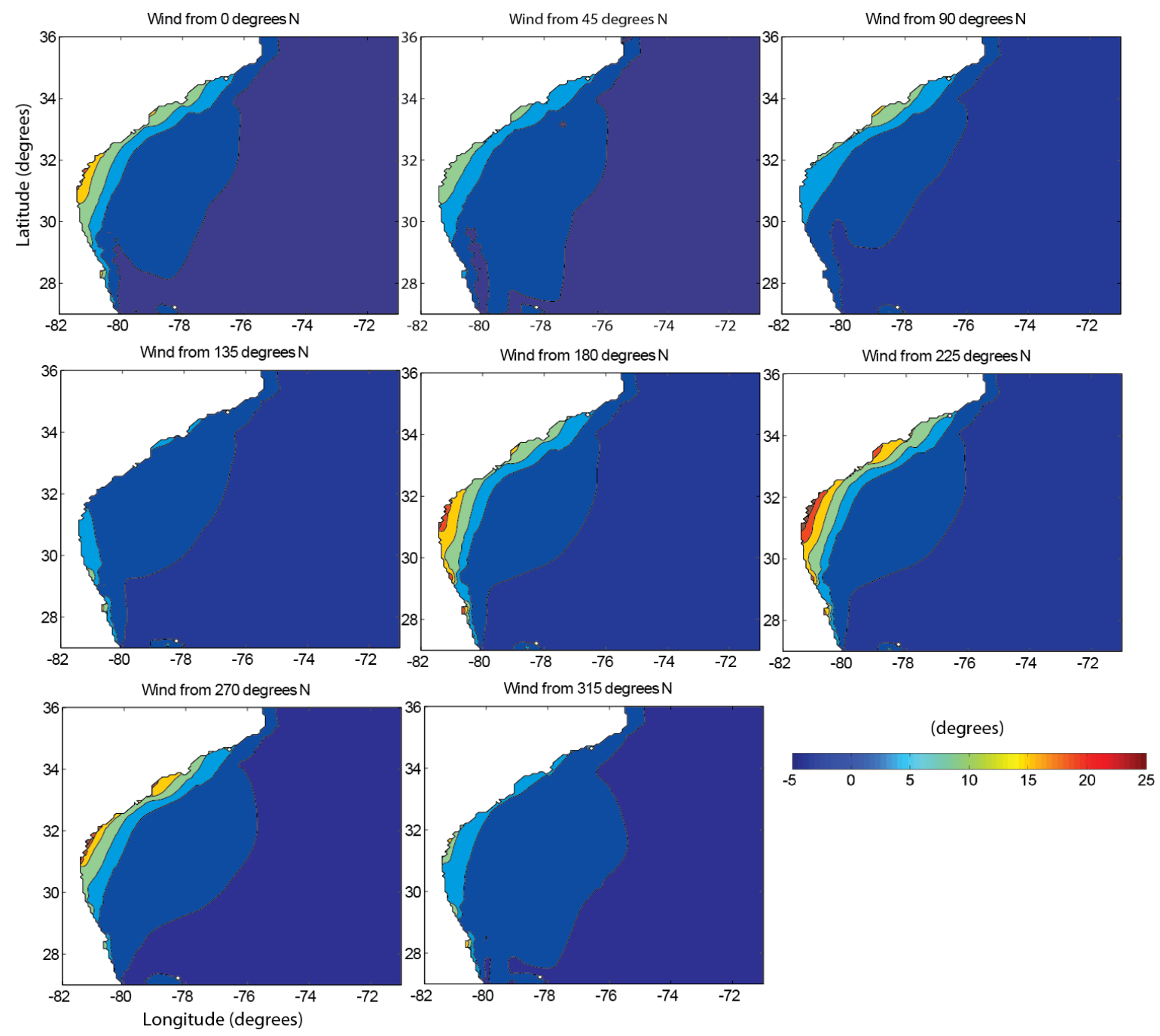

93 Figure 14. Modeled $\mathrm{M}_{2}$ free surface phase variation (degrees) as a function of the wind

94 direction.

95 

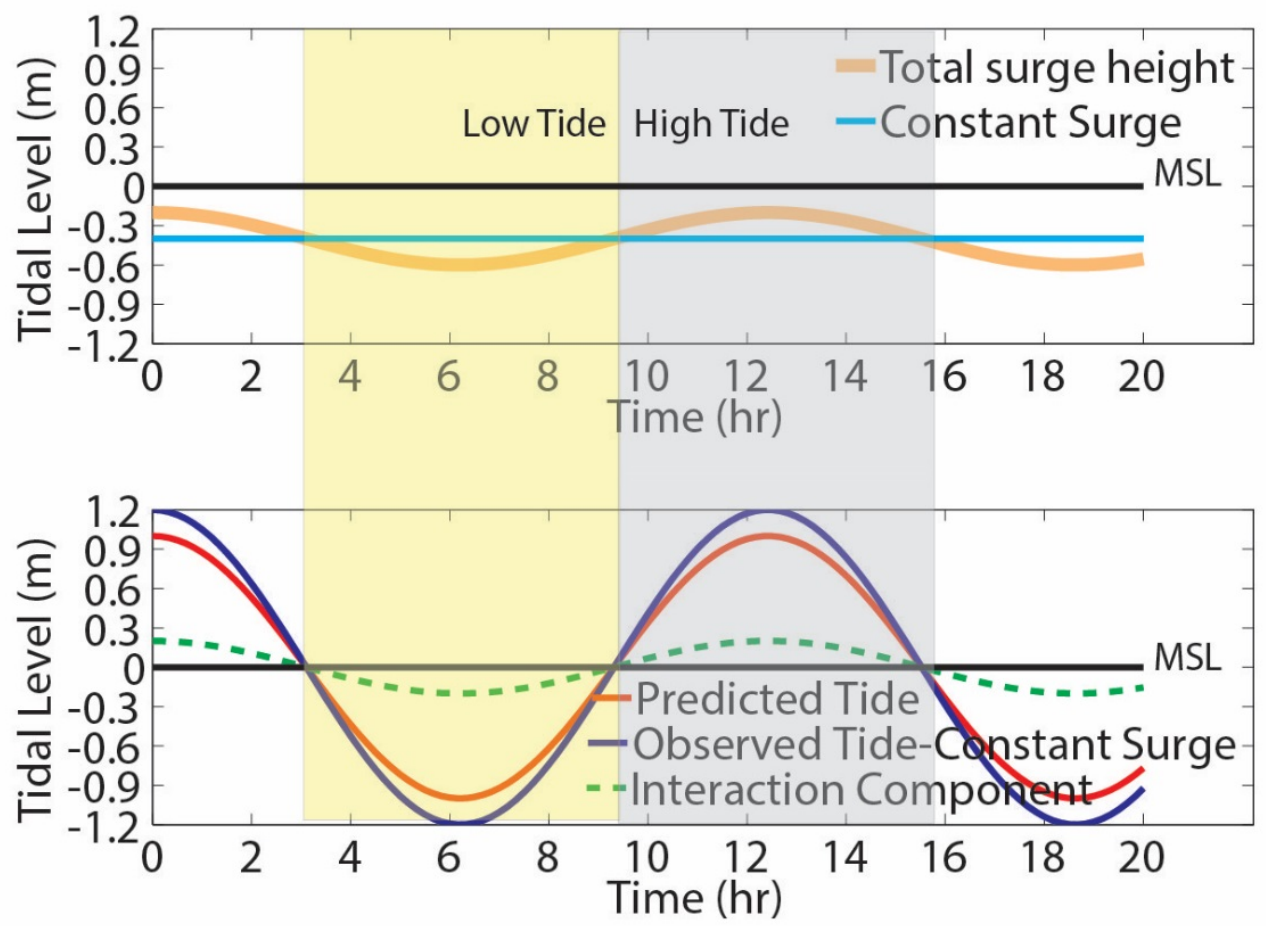

96

97 Figure 15. Schematic diagram of the local surge modification during a negative surge event.

98

99

100 

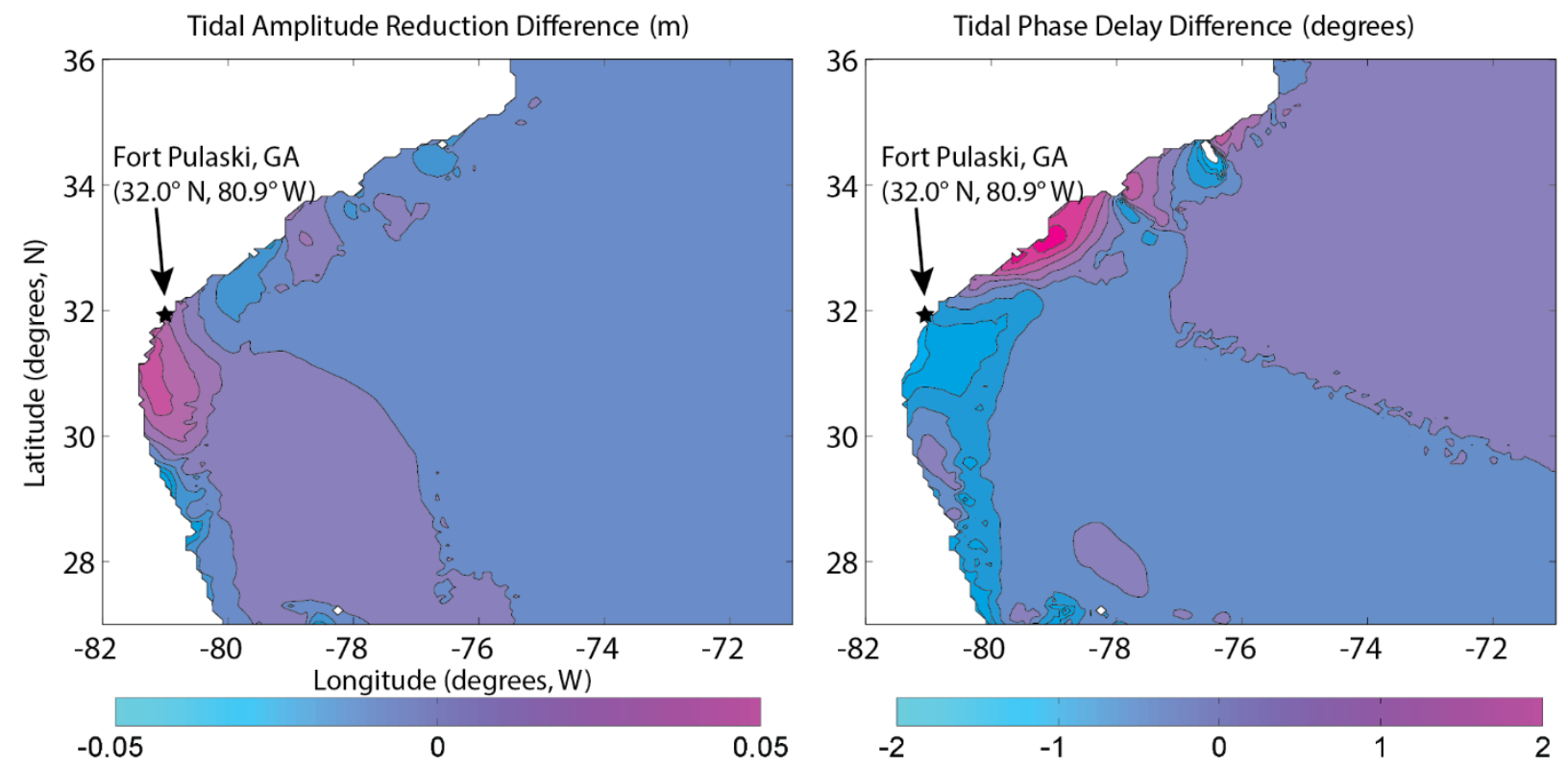

102 Figure 16. Differences between the modeled $\mathrm{M}_{2}$ free surface amplitude reduction (left

103 panel, $\mathrm{m}$ ) and phase delay (right panel, degrees) as a function of the Coriolis force for the

104 NE (45 degrees N) wind case; the differences were calculated by substracting the

105 variables (tidal amplitude reduction, tidal phase delay) under the scenario with

106 consideration of Coriolis acceleration minus the ones without consideration of Coriolis

107 acceleration.

109 Figure 17. Changes in tidal ellipses, inclination angles of the main axises (degrees), and

110 reduction of the main axises of the tidal ellipses $(\mathrm{m} / \mathrm{s})$ for $(\mathrm{A}, \mathrm{B}, \mathrm{C})$ as a function of $\mathrm{NE}$ winds

111 and without the effects of the Coriolis acceleration; (D,E,F) as a function of NE winds

112 and with the effects of the Coriolis acceleration; and $(\mathrm{G}, \mathrm{H}, \mathrm{I})$ as a function of NW winds

113 with the effects of the Coriolis acceleration. In panels A, D and G, the red tidal ellipses

114 are with wind effect, while the gray ellipses are without the wind effect. In the other 
115 panels, the differences are only shown along the continental shelf region, only for 116 shallow water regions (water depth $<50 \mathrm{~m}$ ). 

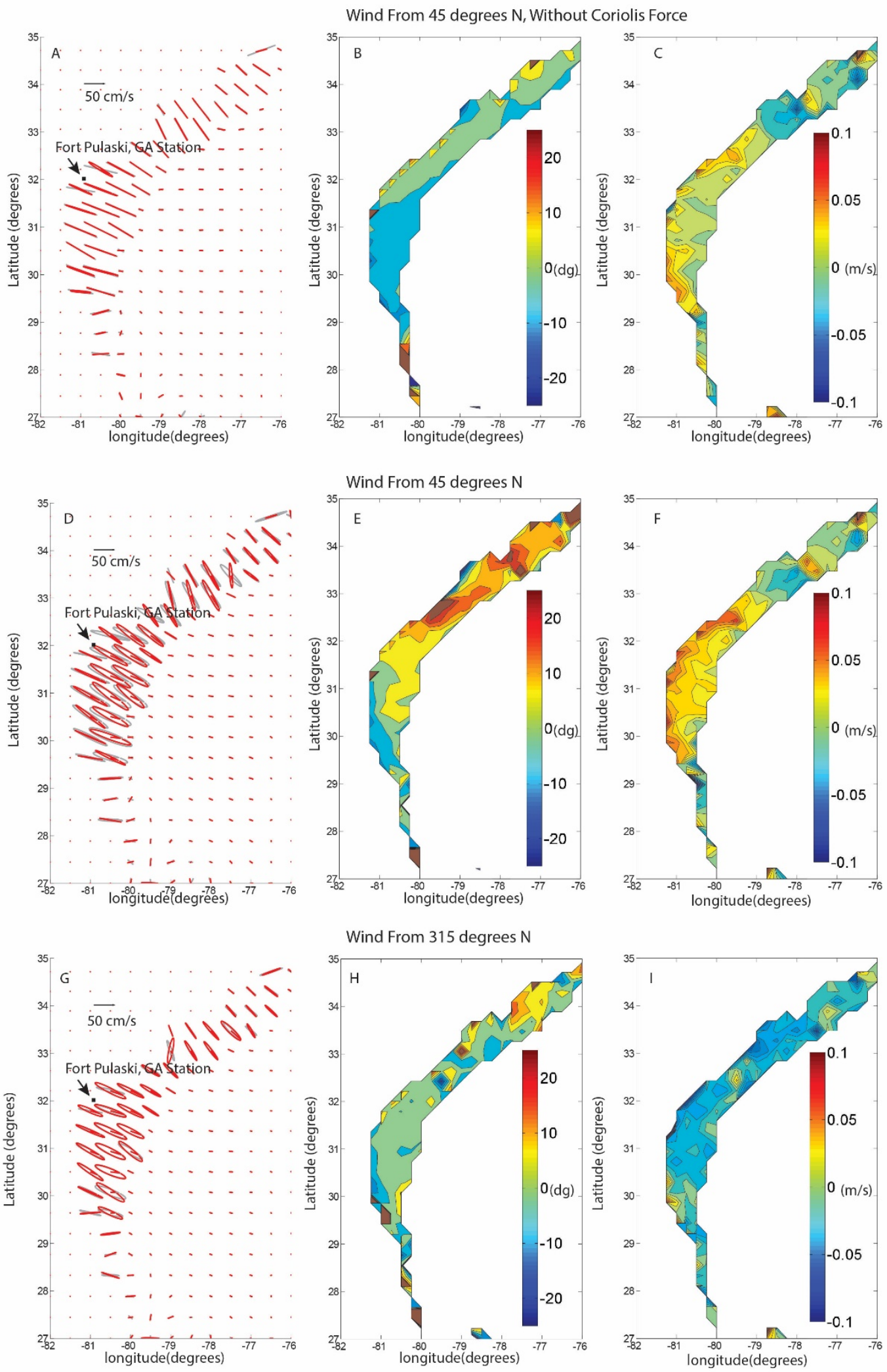

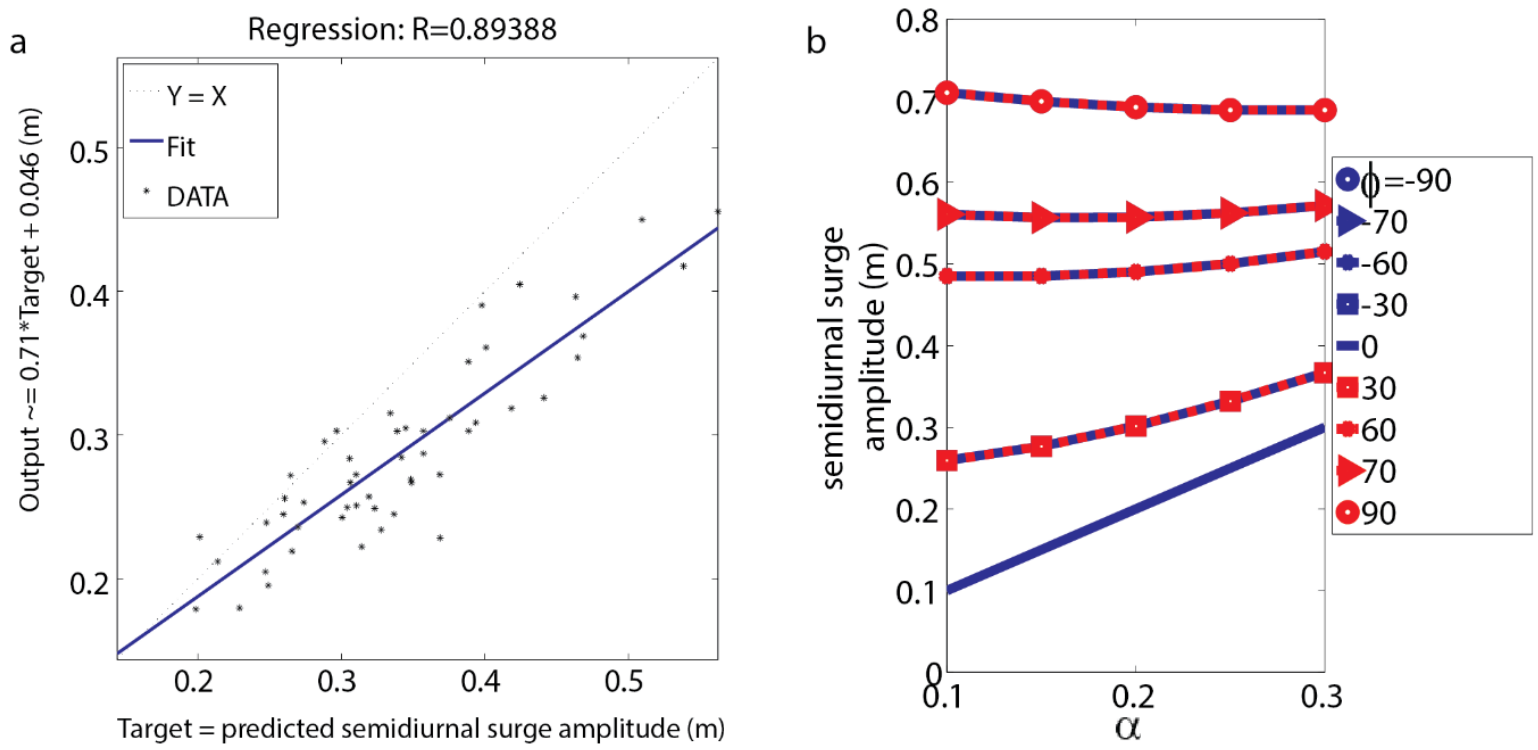

121 Figure 18. a) Regression plot between the predicted semidiurnal surge amplitude at Fort

122 Pulaski (Eq.3) vs. the observed semidiurnal surge amplitude; b) Sensitivity test for the

123 semidiurnal surge amplitude with influence of phase shift $\phi$ and tidal amplitude reduction

124 ratio $\alpha$ ( $\phi$ of the same absolute value share the same marker, but with positive $\phi$ in

125 dashed red and negative $\phi$ in solid blue). 